\title{
Examining Recent HR Data for Gender Bias Among Federal Employees at NIST
}

\author{
Jasmine Evans \\ Amanda Koepke \\ Steven P. Lund \\ Mary F. Theofanos \\ Authors are listed in alphabetical order
}

This publication is available free of charge from:

https://doi.org/10.6028/NIST.IR.8363

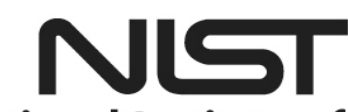

National Institute of Standards and Technology U.S. Department of Commerce 


\title{
Examining Recent HR Data for Gender Bias Among Federal Employees at NIST
}

\author{
Jasmine Evans \\ Information Access Division \\ Information Technology Laboratory \\ Amanda Koepke \\ Steven P. Lund \\ Statistical Engineering Division \\ Information Technology Laboratory \\ Mary F. Theofanos \\ Office of Data and Informatics \\ Material Measurement Laboratory
}

This publication is available free of charge from:

https://doi.org/10.6028/NIST.IR.8363

March 2021

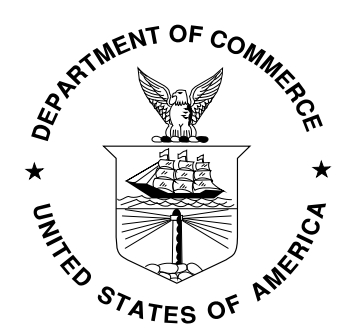

U.S. Department of Commerce Gina M. Raimondo, Secretary

National Institute of Standards and Technology James K. Olthoff, Performing the Non-Exclusive Functions and Duties of the Under Secretary of Commerce for Standards and Technology \& Director, National Institute of Standards and Technology 
Certain commercial entities, equipment, or materials may be identified in this document in order to describe an experimental procedure or concept adequately. Such identification is not intended to imply recommendation or endorsement by the National Institute of Standards and Technology, nor is it intended to imply that the entities, materials, or equipment are necessarily the best available for the purpose.

National Institute of Standards and Technology Interagency or Internal Report 8363

Natl. Inst. Stand. Technol. Interag. Intern. Rep. 8363, 41 pages (March 2021)

This publication is available free of charge from: https://doi.org/10.6028/NIST.IR.8363 


\begin{abstract}
This report is part of a multi-phase mixed methods project that is designed to provide an in-depth look at the population of National Institute of Standards and Technology (NIST) federal employees to identify factors, attitudes, and processes that might result in genderspecific barriers at NIST. In the current project phase, human resources demographic data, compensation data, and performance data of NIST federal employees from 2011 to 2019 were analyzed to determine any relevant trends. This report details the methodology and results, including the steps of analysis, and summarizes where NIST currently stands regarding workplace gender differences. The results include trends of gender differences in the areas of hiring, pay band, annual salary, and supervisory level. Further analysis identified the highest degree earned as a factor toward gender-specific barriers. Finally, we identified the "broken rung" as a factor limiting advancement of women.
\end{abstract}

\title{
Key words
}

Gender; Gender pay gap; Inequities. 


\section{Executive Summary}

This study analyzes employment records of men and women at NIST to gain a basic understanding of the gender differences at NIST. The goal of the NIST Workforce Demographic Analysis is to provide the organization with data about how inequities related to gender manifest themselves in order to measure how the environment changes over time to provide more equitable experiences

This report describes the analysis of employment records for federal employees at NIST for each year from 2011 to 2019 . The data examined includes demographic data, compensation data, and performance data for 5,608 unique federal employees over the 9 years.

Our analysis identified several instances where the data suggests substantial gender imbalances do not exist. These include starting salaries of new employees, performance evaluation ratings among ZP (Scientific and Engineering) employees, performance bonuses in general, and several Operating Units (OUs) for which our analysis suggested overarching gender-related imbalances in salary or pay band were not present.

Despite past efforts to reduce gender-related imbalances at NIST, important differences still exist as recently as October 2019. The conclusions of our analysis are limited to the demographic covariates included in this study. Further, there are some analyses for which there were too few employees to provide a clear picture of whether substantial differences exist or not.

The following imbalances were identified in our analyses.

- In ZP and ZT (Scientific and Engineering Technician) positions, NIST continues to hire more males than females.

- In ZA (Administrative) and ZS (Administrative Support) positions, NIST continues to hire more females than males.

- Salaries generally favor men in ZA, ZP, and WG (Wage Grade) pay plans.

- Salaries for ZP employees appear to be trending toward gender parity, while salary differences between male and female ZA employees appear to be holding steady and differences for WG employees may be increasing.

- Salaries for ZS employees exhibited near parity until 2014 and may now be favoring women.

- Among ZT employees, salary differences favored men before 2015 and more recently have either favored women or exhibited near parity.

- A higher percentage of ZS women receive the highest performance ratings than ZS men.

- ZP women reach pay band IV more slowly than men at each level of education. ZA women with Bachelor's or Master's degrees reach pay band IV more slowly than ZA men with the same level of education 
- A smaller fraction of ZP women ultimately reach pay band V than ZP men. This difference is most pronounced among employees with a Bachelor's as their highest completed degree.

- Within an OU, the presence and extent of pay band or salary imbalances varies by education level and duty state.

- Throughout the first 20 years of her career in government, a female ZA or ZS employee is half as likely to hold a supervisory role as her male counterpart with the same years of experience in government.

- The highest leadership roles (management positions, SES (Senior Executive Service), ST (Scientific or Professional), and SL (Senior Level) appointments) at NIST continue to be disproportionately held by males.

In some cases, the apparent imbalances referred to above are lessening over the years from 2011 to 2019. However, there were also instances where imbalances appeared to be stable or even becoming greater. These imbalances contribute to the inequity of women at NIST, particularly with respect to the broken rung and the glass ceiling. 


\section{Table of Contents}

1 Introduction 1

2 Methodology 3

2.1 Data 3

2.2 Procedures \& Process 4

2.2.1 General Overview 4

2.2.2 Regression and Smoothing 5

2.2.3 Direct Comparisons and Permutation Tests 5

$\begin{array}{lll}2.2 .4 & \text { Survival Analysis } & 7\end{array}$

3 Results $\quad 7$

3.1 Gender Content $\quad 7$

3.2 Gender Differences in Hiring 10

3.3 Gender Differences in Annual Salary $\quad 12$

$\begin{array}{lll}\text { 3.3.1 Salary Differences for ZPs and ZAs } & 13\end{array}$

3.3.2 Salary differences for ZPs by education level and duty station 14

3.3.3 Salary differences for ZPs by education level within OUs 15

3.3.4 Salary differences for ZPs related to experience 16

$\begin{array}{lll}\text { 3.3.5 Salary differences for ZA employees } & 18\end{array}$

3.4 Gender differences in Pay Band 19

3.4.1 Pay Band versus years in government 20

3.5 Gender differences in Supervisor Level 22

4 Discussion $\quad 22$

5 Conclusions $\quad 24$

References $\quad 26$

$\begin{array}{ll}\text { Supporting Information } & 27\end{array}$

\section{List of Figures}

Fig. 1 Slide presented by NIST Director Copan during a VCAT meeting in October 2019.

Fig. 2 FY 19 NIST total population split into Directorates.

Fig. 3 (Top) FY 19 NIST Employee Population by Pay Plan (N=3,334); (Bottom) Trends from 2011 to 2019 in the proportion of employees who are female by combination of OU class and pay plan.

Fig. 4 Concentration of NIST Employees among Pay Bands III, IV, and V by Pay Plan and Gender.

Fig. 5 Percentage of newly hired federal employees at NIST who are female, broken down by Pay Plan and OU group. 
Fig. 6 Female percentage among of degree recipients in 2017-2018 school year and NIST hires (from 2011 to 2019) for general STEM fields at NIST broken down by Pay Plan and Gender.

Fig. 7 High-level summary of annual salary differences between men and women at NIST.

Fig. 8 Average differences in annual salary between men and women at NIST: Sweep across OUs for ZP employees.

Fig. 9 Average differences in annual salary between ZP men and women at NIST, separated by OU type, duty state, and education level.

Fig. 10 Average differences in annual salary between ZP men and women separated by education level for OUs 63, 68, and 77.

Fig. 11 Annual salary versus years in government for ZP men and women in laboratory OUs, split by highest degree.

Fig. 12 Annual salary differences between men and women at NIST: Sweep across OUs for ZA employees.

Fig. 13 Relationship between pay band differences and salary differences. Pearson's correlation coefficient is provided for each combination of pay plan and education level that had at least 10 distinct comparable groups.

Fig. 14 Chances of achieving pay band IV (top) and V (bottom) versus years in government for ZP employees at NIST. Results are presented by gender (color) and education level (left - Bachelor's degree; center - Master's degree; right - Doctorate). The number of male and female employees represented in the results is reported in each column.

Fig. 15 Chances of achieving pay band IV (top) and V (bottom) versus years in government for ZA employees at NIST. Results are presented by gender (color) and education level (left - High school graduate; center - Bachelor's degree ; right - Master's Degree). The number of male and female employees represented in the results is reported in each column.

Fig. 16 Chance an employee has been a supervisor given their years in government for ZP, ZA, and ZS staff, respectively. The number of male and female employees represented in the results is reported in each panel.

Fig. 17 Median starting salary for newly hired men and women split by pay band and pay plan.

Fig. 18 Annual Performance Rating between men and women at NIST: Top performance ratings were selected for analysis.

Fig. 19 Annual Performance Rating between ZP men and women in the largest three OUs: Top performance ratings were selected for analysis.

Fig. 20 High-level summary of pay band differences between men and women at NIST.

Fig. 21 Pay band versus years in government for ZP men and women in laboratory OUs, split by highest degree. 


\section{List of Acronyms and Abbreviations}

IIS ......... Innovation \& Industry Services

LP ......... Laboratory Programs

MR ........ Management Resources

OU ......... Operating Unit

SES ....... Senior Executive Services

SL .......... Senior Level

ST ......... Scientific or Professional

ZA ........ Administrative

ZP ......... Scientific and Engineering

ZS ......... Administrative Support

ZT ......... Scientific and Engineering Technician

WG ........ Wage Grade 


\section{Introduction}

The National Institute of Standards and Technology (NIST) Director Walter Copan discussed inequities related to gender ${ }^{1}$ at his first Town Hall with NIST staff on July 12, 2018, saying "The statistics have come out very clearly... At the kind of earlier career levels [ZP III/IV], we have roughly $25 \%$ women and roughly $20 \%$ minorities represented. And by the time that we look at the senior levels in the organization, those percentages of diversity, gender, and also in other categories are much less than they should be" [1, 2]. At a Visiting Committee on Advanced Technology (VCAT) meeting in October 2019, Dr. Copan presented the same human resources (HR) data showing that female scientists and engineers are decreasingly represented at escalating levels of leadership, shown in the slide from that meeting in Figure 1. The 2015 HR data illustrated that one out of every four researchers in ZP pay bands III and IV were women, but only one in 11 STs or NIST Fellows were women. This is in spite of the fact that the time-in-service distribution of ZP females was nearly identical to that of ZP males. At a NIST Managers and Supervisors Meeting on Inclusivity in April of 2019, Dr. Copan emphasized that "we had a long way to go" [3].

Gender Diversity in NIST's S\&T Workforce
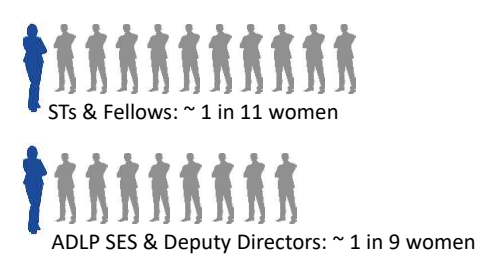

mimtition

ZP V: 1 in 6 women

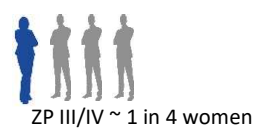

Data presented in NIST July 2018
NGT

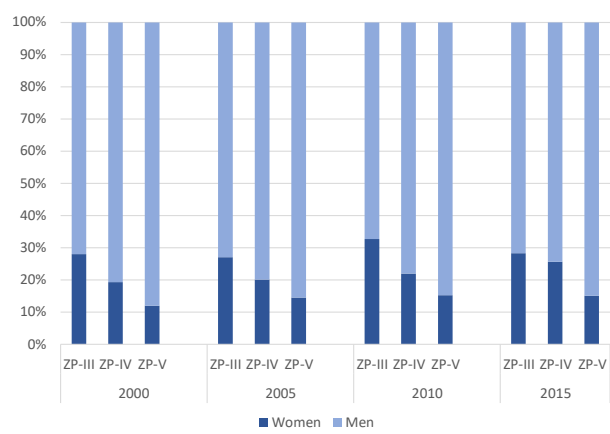

At all points in time, women make up a smaller share of the higher pay bands

Fig. 1. Slide presented by NIST Director Copan during a VCAT meeting in October 2019.

In 2019 many OUs embarked on diversity and inclusivity initiatives; one initiative particularly relevant to the current analysis is the work of MML's Chief of Staff, Dr. Christopher Szakal, and Senior Management Advisor, Frannie Johnson, who developed a tool to

\footnotetext{
${ }^{1}$ The available data on the sex/gender of NIST employees comes from HR asking employees to self-identify their sex, with male and female as the only response options. While there is a difference between the terms man/woman (usually referring to gender) and male/female (used to refer to sex), for our analyses the terms are used interchangeably. We recognize that gender is a far more complex category - but given the data provided by HR we are limited in what can be addressed in this report.
} 
analyze gender equity in hiring and promotions [4, 5]. In April 2019, the NIST Associate Director for Laboratory Programs, Dr. James Olthoff, sent an email to all staff calling for proposals for a funded opportunity to study equity, diversity and inclusion. In the email he stated, "As you know, over the past year NIST has taken steps toward addressing issues of equity in career advancement at NIST. These include the creation of a new Steering Group on Equity in Career Advancement, increased dialogues about equity issues in each of the laboratories, and discussion-based Equity Café events on our Boulder and Gaithersburg campuses. While these steps have been helpful, there is much more to do." The Equity Cafés $[6,7]$ were designed to "discuss what staff and leaders can do to identify and remove barriers that impede women and minorities, improve opportunities for advancement for everyone, and promote an equitable and inclusive working environment", and "observations that NIST staff members shared during the December 13, 2018, and March 7, 2019, Equity Café events further reinforced that we should do more to achieve an equitable work environment at NIST" [8].

NIST leadership recognizes that equity and inclusion challenges are real, exist at NIST, and require intervention. Despite previous attempts in the last thirty years to address inequities and create a more inclusive environment, gender inequities at NIST persist today. Given this backdrop, the goal of this project and our analysis was not to prove that these inequalities exist, but instead to examine multiple years of HR data to highlight specific areas where inequalities manifest. The analyses we have developed could serve as metrics to evaluate how NIST is doing over time and a lens through which we can look at NIST HR data.

Additionally, we explored other areas where the literature [9] describes inequities, such as the glass ceiling, broken rung, and salary differences. A 1986 article in the Wall Street Journal on women in the workplace coined the term "glass ceiling" to describe the experience of women who seemed unable to reach the highest levels of corporate success. But according to a report on Women in the Workplace [10] a bigger obstacle to women's progression is the "broken rung" or the first step up the ladder to manager. The underrepresentation of females in leadership positions at NIST suggests that NIST is not immune from the common challenges in gender equity, but it is important to have concrete evidence about these topics from the data.

A growing body of literature describes strategies for diversity and inclusivity, most notably the National Academies report on Promising Practices for Addressing the Underrepresentation of Women in Science, Engineering, and Medicine: Opening Doors [11]. Many companies including Google [12], Uber [13] and Rockwell Automation [14] have shared lessons learned from their diversity and inclusivity initiatives. A key component for success in all of these organizations is continuous data collection and monitoring across all of the phases of program implementation with a particular focus on recruitment, retention, and advancement of women. "When you can measure what you are speaking about, and express it in numbers, you know something about it, when you cannot express it in numbers, your knowledge is of a meager and unsatisfactory kind; it may be the beginning of knowledge, but you have scarcely, in your thoughts advanced to the stage of science"(Lord 
Kelvin). The first step in promoting systemic change to address gender inequities is to measure and establish a baseline of the organization. Data must continue to inform the diversity, equity, and inclusivity work. As the preeminent metrology institution in the world, measurement informs everything NIST does, so measurement should be the foundation for building a more representative workforce. This effort begins by collecting human resource data from recent years to establish a baseline and to develop an evaluation framework that will provide transparency and accountability in the reporting progress for issues regarding underrepresentation and inequity.

This report addresses the first of three phases of a project funded as part of an ongoing effort to identify and address areas of potential gender inequity throughout NIST. Phase 1 examines HR data for evidence of sources of inequities. Phase 2 uses in-depth interviews to gather staff perceptions and experiences of women and men at NIST. Finally, phase 3 surveys all federal employees at NIST to determine the extent that employees at NIST perceive gender inequities.

\section{Methodology}

In this section we describe the data elements used in the analysis as well as the overall approach to the analysis. We also describe the tools used and detailed descriptions of the statistical techniques.

\subsection{Data}

This document focuses on a review of employment records for federal employees at NIST for each year from 2011 to 2019. Data was pulled on January 10, 2020. Data prior to 2011 would be difficult to integrate into the analysis due to the reorganization of NIST in 2010. The records were provided by NIST OHRM and includes demographic data, compensation data, and performance data. Each record included the following fields for each federal employee:

- annual salary

- yearly bonus amount

- pay plan (ZP, ZA, ZS, ZT, WG, ST, SL, SES)

- pay band (I - V for ZP, ZA, ZS, ZT)

- operating unit $(\mathrm{OU})$

- position title

- gender

- age 
- NIST assigned workplace location (duty station)

- employment status

- years of service at NIST

- years of service in the Federal Government

- supervisory status

- performance rating

- education level

Employee names were specifically excluded to protect identities. Instead, employees were assigned a unique numeric identifier so that they could be tracked from one year to the next. There are 5,608 unique federal employees in the 9 years of HR data.

\subsection{Procedures \& Process}

\subsubsection{General Overview}

Our evaluations sought to identify whether there were any apparent gender imbalances in hiring, performance evaluation, salary, pay band, or supervisory roles. Analyses were conducted separately for each year from 2011-2019 to assess potential trends, especially for analyses in which gender imbalances were apparent. The idea is to see whether apparent imbalances are lessening, becoming greater, or holding steady.

Throughout our analyses, we evaluated various cross sections of NIST, often grouped by OUs, pay plans, and levels of education. For OUs, we conducted analyses for all of NIST (all OUs), the Laboratory Program OUs (OUs whose first two digits of identification numbers are between 60 and 77), Management Resources OUs (OUs whose first two digits of identification numbers are 10,11, between 13 and 19), and Innovation and Industry Services OUs (OUs whose first two digits of identification numbers are 40, 45, 47, 48, and 49). For pay plans, we analyzed ZP (Scientific and Engineering), ZA (Administrative), ZT (Scientific and Engineering Technician), ZS (Administrative Support), and WG (Wage Grade) separately. For education level, the highest completed degree was used (e.g., High school diploma, Associate's or trade school degree, Bachelor's degree, Master's degree, Professional degree, Doctoral degree). While many cross sections of the data provided meaningful insights, certain subsets had too few employees to provide a reasonable basis for evaluation.

As tools for general overviews, we use stacked bar plots, where the height of the bar shows the total, and different colors of the bar denote the relative sizes of different subgroups of the total. 


\subsubsection{Regression and Smoothing}

To reasonably assess potential gender-related imbalances in salary, pay band, or supervisory roles, we will clearly need to account for the effect of years of experience. Our first efforts were to include polynomials of years of experience as variables in multiple regression models. We sought to allow flexible models to "let the data speak", but found that predictions representing interpolations and extrapolations for these models were often implausible. We then used stronger assumptions to constrain how average salaries, pay bands, or chances of being a supervisor evolve with experience (and how these trajectories and the variability in the data around the trajectories are related across other important factors like education level or OU), but felt unsure whether the results were more a reflection of our assumptions than of the data.

We eventually settled on using cubic polynomials (smoothing curves) to fit years-ofexperience related trends in salary and pay band for high-level cross-sections of the data (e.g., ZP staff in laboratory OUs, separated by highest degree). This approach has the benefit of there being enough employees to reasonably guide the smoothing curve but the detriment of grouping several OUs, any of which may differ from another, together as though they behave identically.

\subsubsection{Direct Comparisons and Permutation Tests}

After implementing the regression and smoothing analyses, we sought to develop analyses that meaningfully compared data to data, rather model prediction to model prediction. We use the resulting strategies to conduct many comparisons of either salaries or pay bands for men and women at similar career points. To make 'apples to apples' comparisons, we controlled for factors like education level, pay plan, OU, duty station, and professional experience (definition provided below). We search the HR data to find employees that match on all the above factors and differ in their genders, and calculate the difference between their salaries and pay bands. If there are no matches for the exact number of years of experience, we use the fact that we have data for multiple years to find a matching employee who had the same experience level within a nearby calendar year (not more than two calendar years apart), and compute the difference between the matching employees when they both had the same years of experience. For example, suppose when examining data for 2017, a given combination of education level, pay plan, OU, and duty station contains only one woman and one man, where the woman has one more year of experience than the man. Rather than ignoring data from both these employees, we compare the 2016 data for the woman, if present, to the 2017 data for the man, and, similarly, compare the 2018 data for the man, if present, to the 2017 data for the woman. Note that all salaries are compared in terms of 2019 dollars, which have been scaled so that the lower bound of the ZP V salary range is constant year over year within each duty state.

The HR data provides a somewhat limited picture of any given employee's work history prior to 2011, the first year of the dataset. Getting an accurate representation of each person's past would require meeting individually with every NIST employee to discuss their 
past experience, which would explicitly violate efforts to maintain anonymity. Thus, we are left with imperfect information with which to characterize each employee's professional experience. Given this limitation, we conducted our salary and pay band comparisons considering two different measures of professional experience. We first used employees' years of service in government to characterize their professional experience. This variable ignores any professional experience outside of being a federal employee and therefore underrepresents the experience of people who worked in industry or academia before joining NIST. We repeated the analyses while representing experience as the maximum of the years each employee has been in government and the years since they received their highest degree. The additional consideration of years since degree would help capture work experiences occurring between the time they earned their highest degree and the time they became a federal employee. However, this still does not capture non-government work experiences that occurred before the time of their highest degree (e.g., a person who worked 5 years in industry then went back to school to earn a Ph.D. and subsequently joined NIST). It also presumes that each person worked continuously between the time they earned their most recent degree and the time they became a federal employee. For instance, if someone took substantial time off to travel or focus on family between earning their highest degree and joining NIST, those years would be counted the same as having worked at NIST continuously after earning their degree. The results of our analyses focusing on pay band and salary were nearly identical regardless of which of the two imperfect representations of experience were used. This helps alleviate concern that our results would be highly sensitive to the missing information that would better define professional experience.

Once we have a set of comparable employees, we can look at the average differences in salary or pay band for each year of HR data. We evaluate whether the average differences indicate a statistically significant gender bias using permutation tests. Briefly, the permutation tests evaluate how often shuffling the gender labels within each comparable group leads to an average difference as severe as or more severe than the average difference computed using the actual gender labels in the HR data. We report one-sided p-values for each observed difference that are based on 4999 simulated permutations plus the original value. For negative differences, we report the proportion of permutations that produced values as low as or lower than the originally observed difference. For positive differences, we report the proportion of permutations that produced values as large as or larger than the originally observed difference.

When breaking the results into smaller groups, such as individual OUs, there is less data to work with compared to the high-level summary analysis. This leads to less statistical power to establish differences of a given magnitude as statistically significant. We assumed in each analysis that the average difference between the groups is zero and sought data to prove otherwise (p-value less than 0.05). It is important to recognize that failure to find proof of a difference ( $\mathrm{p}$-value greater than 0.05) does not mean the average difference is essentially zero, especially when the average is taken over a small number of comparisons. Assessments of statistical significance are made for each year, respectively, so year-to-year patterns are not reflected in the presented p-values. An informal overall assessment of how 
strongly the data suggest a meaningful imbalance might also consider the consistency of the direction and magnitude in the computed differences from year-to-year (e.g., whether the average difference is positive in all nine years or negative in all nine years). In order to characterize a given cut of the data as suggesting that the corresponding subset of NIST employees does not exhibit potential gender imbalances, we required some years to have positive differences and others to have negative differences, with none being statistically significant, no obvious temporal trend (e.g. a strongly linear increase or decrease across time), and no extreme values.

\subsubsection{Survival Analysis}

When evaluating chances that men and women achieve higher pay bands or supervisory positions as they progress through their career in government, we are often missing the exact year where employees first achieve those positions. For instance, for individuals that moved from a non-supervisory role into a supervisory role during years 2012 through 2019, the HR data reveals the precise point in their career when they became supervisors. Many supervisors already held their supervisory position in 2011, the first year for which we have HR data. For these individuals, we know they were supervisors in 2011, but do not know the precise point in their careers that they first became supervisors. Fortunately, statistical survival analysis tools exist to fully utilize the complete blend of precise and imprecise (censored) data, such as this. We use these tools to construct curves for men and women, respectively, that relate the chance of having been a supervisor at any point during 2011 to 2019 (or the chance of reaching pay bands IV and V) to the number of years worked in government.

\section{Results}

In this section we present the results of the analyses performed. It is not possible to present all of the analyses that were performed in this effort. In this section we focus on and present the results where gender imbalances were identified. The analysis also included several instances where the data suggests substantial gender imbalances do not exist. These include starting salaries of new employees, performance evaluation ratings, performance bonuses in general, and several OUs for which our analysis suggested overarching salary or pay band imbalances were not present.

The first section describes the current demographics of the federal employees across the organization. The remaining sections examine gender differences in hiring, annual salary, pay bands and supervisory positions.

\subsection{Gender Content}

What does NIST look like today? This section describes the current composition of the federal employees across NIST. We present demographic data with respect to gender, age, 
years of service, pay plans, pay bands, and supervisory positions for NIST as a whole, for the three Directorates and for the Operating Units (OU).

Looking at the last year of available data (2019), sixty-five percent (65\%) of federal employees at NIST are male, and $35 \%$ are female, from a total population of 3,334. This has been a consistent percentage across NIST over the past nine years and little difference in the last 27 years, according to a 1993 report on female scientists and engineers at NIST [15], which stated that women represented $32 \%$ of the workforce at NIST. Employee ages at NIST range from 16 to 88 years. The median age of males and females is 48 and 47 years, respectively. The average length of service for both male and female employees at NIST is 12 years.

Of the 3,334 employees, 2,209 are in Laboratory Programs (LP) (68\% male, 32\% female), 1,027 are in Management Resources (MR) (59\% male, 41\% female), and 98 are in Innovation \& Industry Services (IIS) (45\% male, $55 \%$ female).

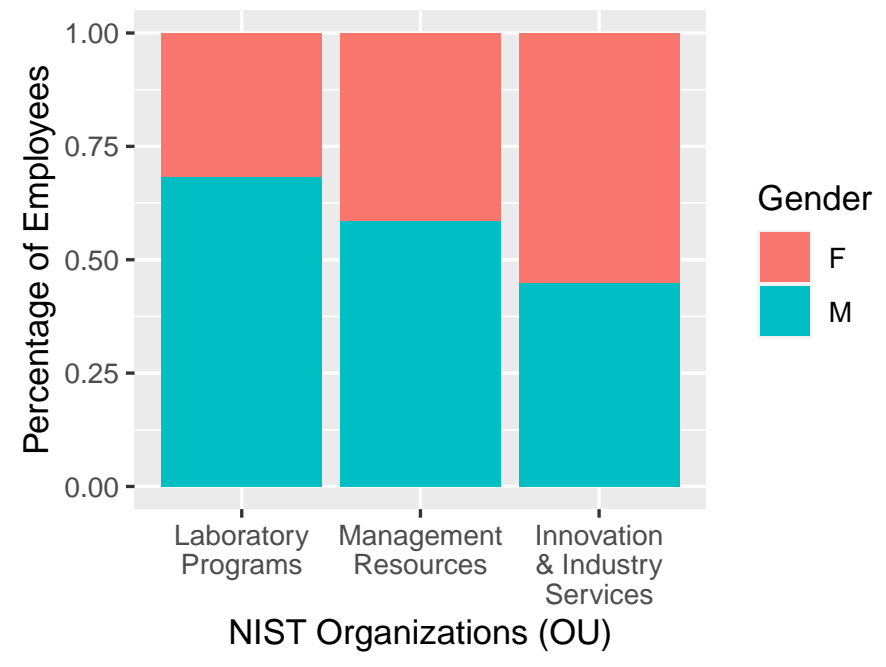

Fig. 2. FY 19 NIST total population split into Directorates.

Out of a total of 471 supervisors at NIST in 2019, 136 were female (29\%), while 335 were male $(71 \%)$. In the 120 year history of NIST, NIST has had one female Director out of 16 total Directors (6\%). In 2019, the three Associate Directors (AD) were males; in July 2020, NIST hired a woman as one of its Associate Directors. As of July 2020, 4 of 19 OU Directors are women (21\%), 4 women are in the Senior Executive Services (SES) out of a total of $25(16 \%)$, and 2 STs or NIST Fellows are women out of 38 total (5\%). Additional upper-level positions at NIST consist of Division Chiefs $(\mathrm{N}=88)$ and Group Leaders $(\mathrm{N}=228)$. Currently, $37.5 \%$ of Division Chiefs at NIST are women and $22 \%$ of Group Leaders are women. Among the NIST portrait gallery that recognizes distinguished scientists, engineers, and administrators for outstanding career contributions to the work of NBS/NIST, 29 out of 339 (8\%) of those portraits are of women.

We examined the number of men and women in each pay plan at NIST. The top panel of Fig. 3 shows that there are more men in SES, ST (Scientific or Professional), and SL 
(Senior Level) roles than women. Conversely, more women than men occupy the ZA and ZS roles. Men also dominate NIST's largest pay plan, ZP, at $75 \%{ }^{2}$. The pay plan with the highest percentage of women is ZS at 77\%. The bottom panel of Fig. 3 shows that the gender distribution within most combinations of pay plan and OU type has been largely stable from 2011 through 2019.

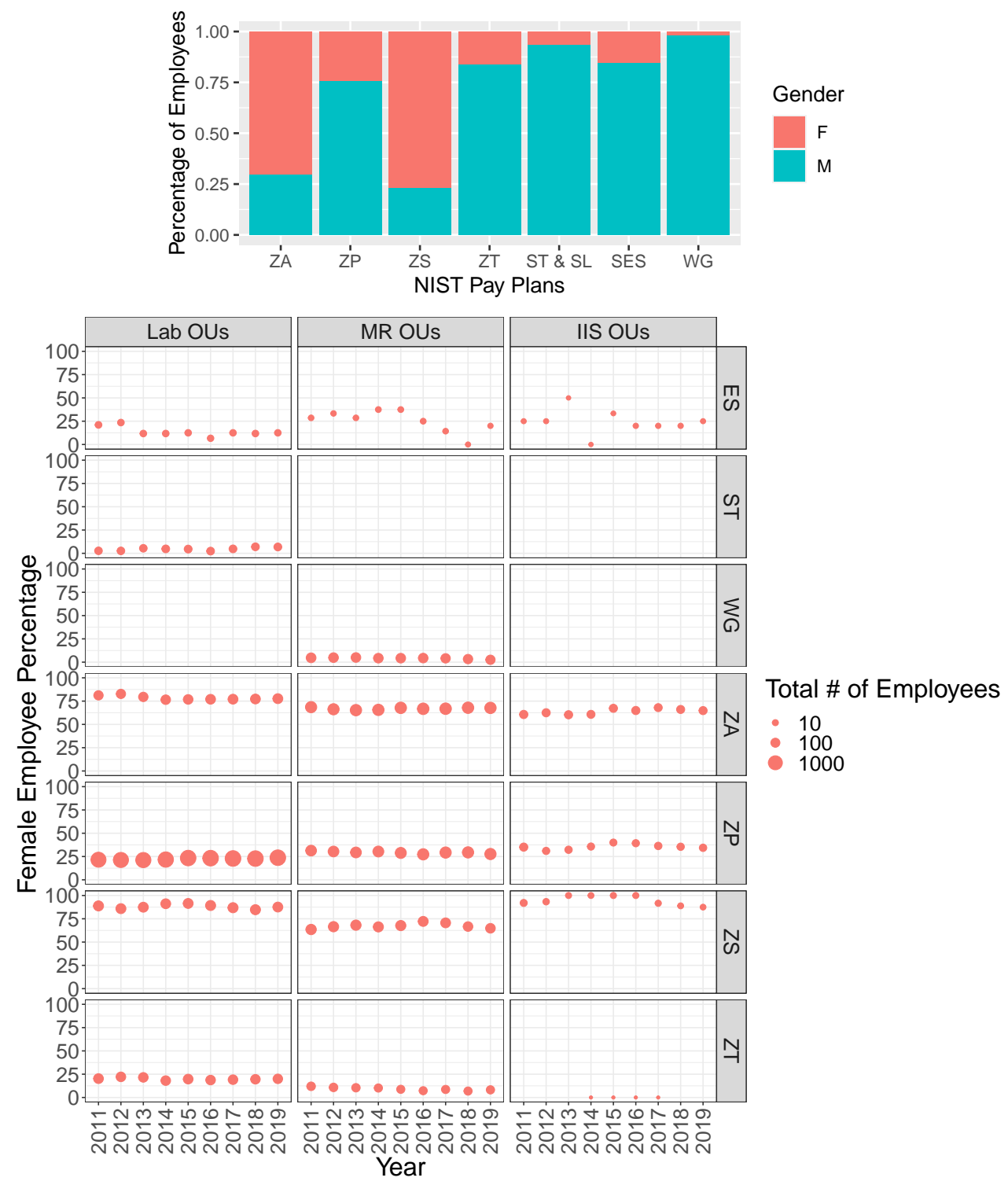

Fig. 3. (Top) FY 19 NIST Employee Population by Pay Plan $(\mathrm{N}=3,334)$; (Bottom) Trends from 2011 to 2019 in the proportion of employees who are female by combination of OU class and pay plan.

${ }^{2}$ This represents a significant increase in women in the ZP pay plan. The percentage of ZP women has increased since 1993 , from $14 \%$ to $24.54 \%$. 
Figure 4 provides a further breakdown of men and women across the pay bands within a pay plan and shows that the imbalances in the distribution of male and female ZP employees in the different pay bands from 2015 that were referred to by Dr. Copan still persist today. Every year from 2011 to 2019, for ZP, ZA, and ZT pay plans, the proportion of women at pay band III (the lowest pay band considered in this analysis) is larger than it is for men, and the proportion of women at pay band V (the highest pay band) is lower than it is for men. The pay band distributions for employees on the ZS pay plan do not exhibit such clear trends between gender.

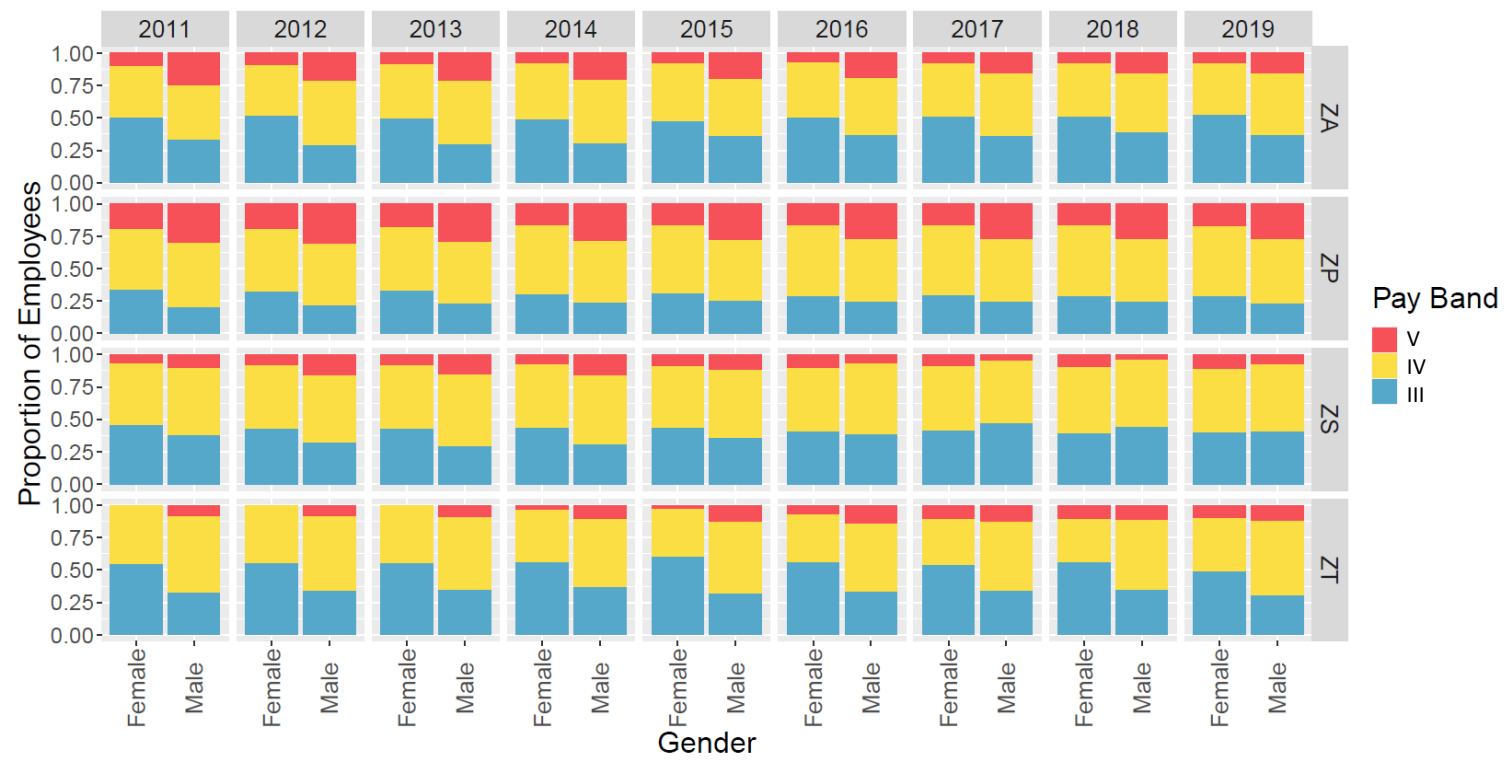

Fig. 4. Concentration of NIST Employees among Pay Bands III, IV, and V by Pay Plan and Gender.

\subsection{Gender Differences in Hiring}

The gender breakdown for the new NIST hires is shown below in Fig. 5. The plot shows that:

- NIST is consistently hiring more men than women for the ZP and ZT pay plans.

- NIST is hiring more women than men for the ZA and ZS pay plans.

- Among those representing at least 20 hires per year, hiring percentages have changed very little over the nine years analyzed.

Evaluating the hiring practices of NIST for evidence of discriminating applicants based on gender would ideally involve looking at the pool of potential applicants, the pool of actual applicants, how far each applicant made it in the interview process, who was offered 


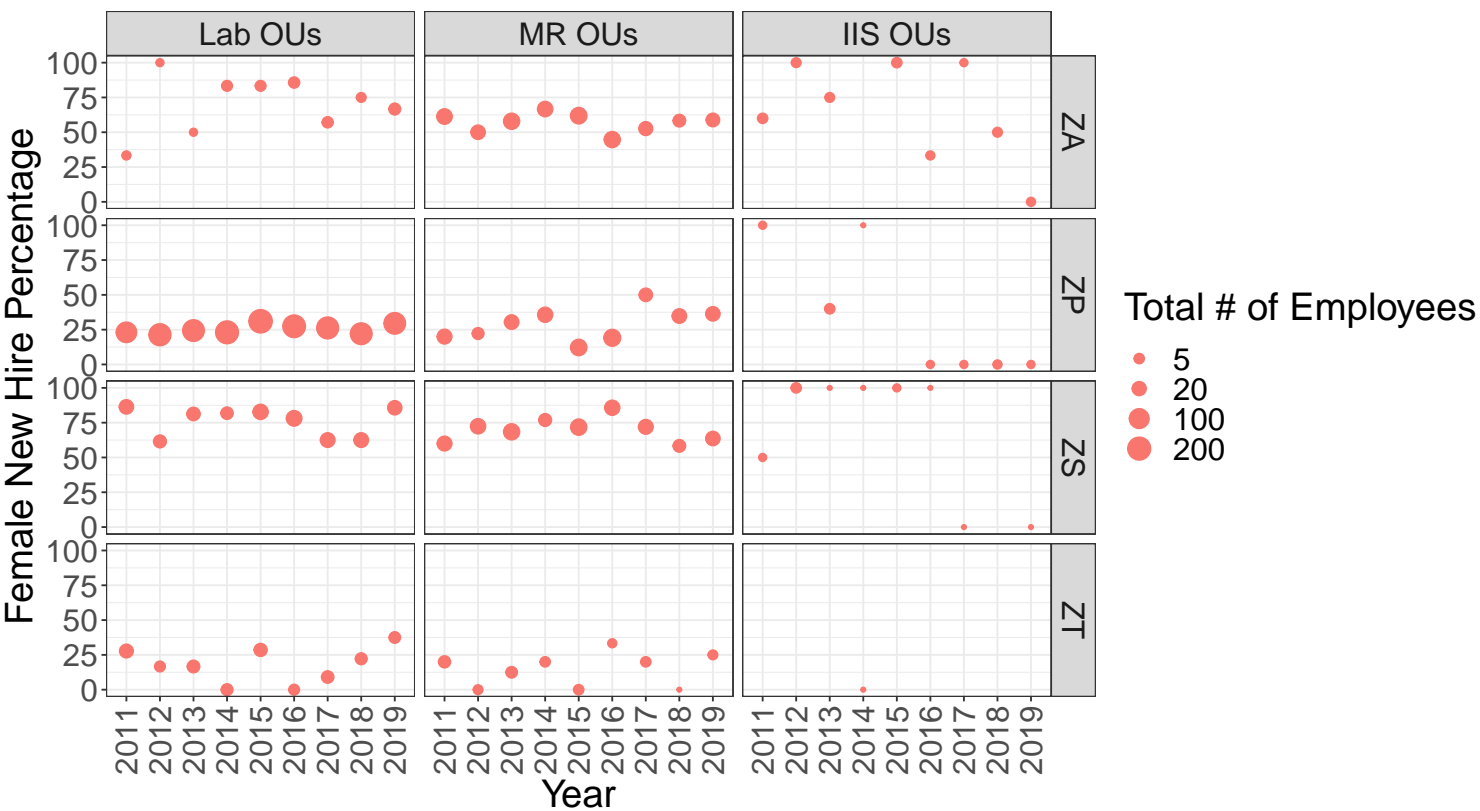

Fig. 5. Percentage of newly hired federal employees at NIST who are female, broken down by Pay Plan and OU group.

a position, and who accepted a position. We are able to form a partial representation of this system using the HR data and tabulations of the number of Bachelor's, Master's, and Doctorate degree recipients by gender in broad STEM fields, compiled for the 2017-2018 academic year as reported by the National Center for Education Statistics [16]. In particular, the National Center of Education Statistics numbers for degree recipients represents the "pool of potential applicants" (in 2017-2018) and the new hires in the HR data represent "who accepted a position" (aggregated over 2011-2019). Comparing these two, as done in Fig. 6, shows that the gender distribution for the output of the hiring pipeline (i.e., pool of new NIST ZP employees in STEM fields) matches, at least roughly, those from the corresponding pools of doctorate recipients from 2017-2018. However, the percentage of female degree recipients (and NIST hires) is far below 50\% for many STEM fields. As an internationally renowned institute of science and metrology, NIST can leverage its reputation by ensuring that the recipients of high-profile awards and positions of leadership reflect the gender balance it hopes to actively promote among those who enter and complete advanced degrees in these STEM fields. 


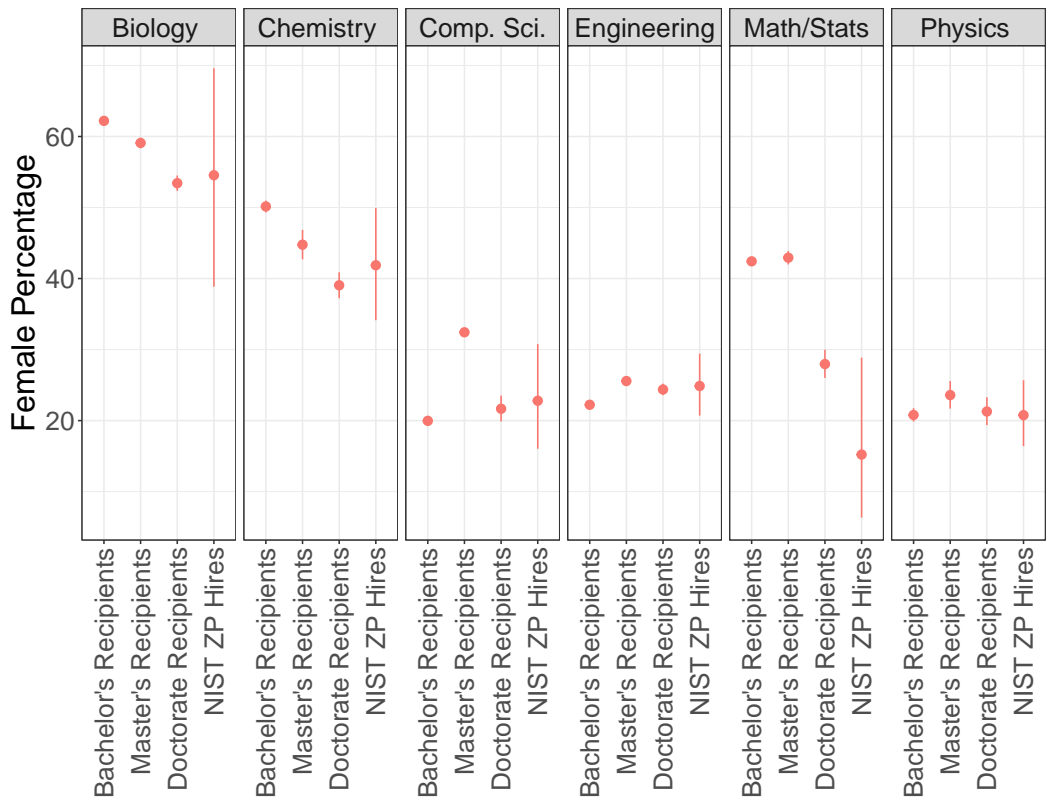

Fig. 6. Female percentage among of degree recipients in 2017-2018 school year and NIST hires (from 2011 to 2019) for general STEM fields at NIST broken down by Pay Plan and Gender.

\subsection{Gender Differences in Annual Salary}

To examine possible differences in annual salary between comparable men and women, we first conduct the comparative analysis described in Sec. 2.2.3. For a man and woman who have the same amount of experience, degree, OU, pay plan, and duty station, we calculate the difference between their salaries (in 2019 dollars according to COLA adjustments) and plot the average of these differences among various subsets of NIST in the plots below. This is done for each year separately so we can look at trends over time. While the amount of experience, degree, OU, pay plan, and duty station are not always visible in the figures, they are all used to determine which employees are comparable in every figure in this section that presents average differences. Fig. 7 provides an overview of average salary differences across NIST for combinations of pay plans and OU type. The results show that for

- WG employees: there are relatively few employees in the WG pay plan. The limited available comparisons suggest there may be a current salary difference favoring men of roughly $\$ 17,000$. An increasing trend in this difference is observed over the nine years of data included in the study.

- ZA employees across NIST: over the nine years observed, there appears to be a fairly constant salary difference favoring men of around $\$ 7,500$. This difference appears most severe for ZA employees in IIS OUs, with males making an average of roughly $\$ 15,000$ more per year than their female counterparts. 
- ZP employees across NIST: There appears to be a salary difference favoring men of roughly $\$ 1,000$ in 2019 . This follows a steady decreasing trend from an initial difference of roughly $\$ 4,500$ in 2011 . While the largest source of ZP employees (laboratory OUs) follow the NIST-wide observations, larger differences between salaries are observed in the MR and IIS OUs. In MR OUs, males made an average of roughly $\$ 2,500$ more per year than their comparable female counterparts in 2019 (down from about $\$ 7,000$ in 2011).

- ZS employees across NIST: Though few observations were found to be significantly different from zero, the average salary difference favored women in seven out of nine years. The laboratory OUs showed the greatest imbalance among ZS employees, in which an average salary difference of about $\$ 3,500$ favored women over the nine years and exceeded $\$ 5,000$ in 2016 .

- ZT employees: there are very few directly comparable men and women among ZT employees according to this analysis. Across all of NIST, we observe a decreasing trend beginning with the salary difference favoring men and favoring women in two most recent years.

\subsubsection{Salary Differences for ZPs and ZAs}

In the following section we break down the differences in salaries for ZP and ZA employees by various combinations of OU, education level, and duty state. The small number of pairs of comparable men and women limited the value of further refinements for ZS and ZT employees. In the following figures, results for a given year are only plotted if there were at least four direct comparisons available for that year. Results for a given OU are only plotted if there were at least four such years.

In Fig. 8, we see that trends for the ZP employees vary by OU. The results show that:

- Of the 93 salary comparisons displayed in Figure 8, 72 comparisons are positive, meaning salary differences tend to favor men.

- For OUs 18, 68, 73, and 77, the average salary differences favor men in all nine years, but clearly lessen between 2011 and 2019, with the smallest differences occurring in 2018 and 2019.

- The average salary differences for OU 61 favors men in all nine years, and the largest differences occur in 2018 and 2019.

- The average salary difference for OU 67 favored women in all years except 2019, when it favored men. 


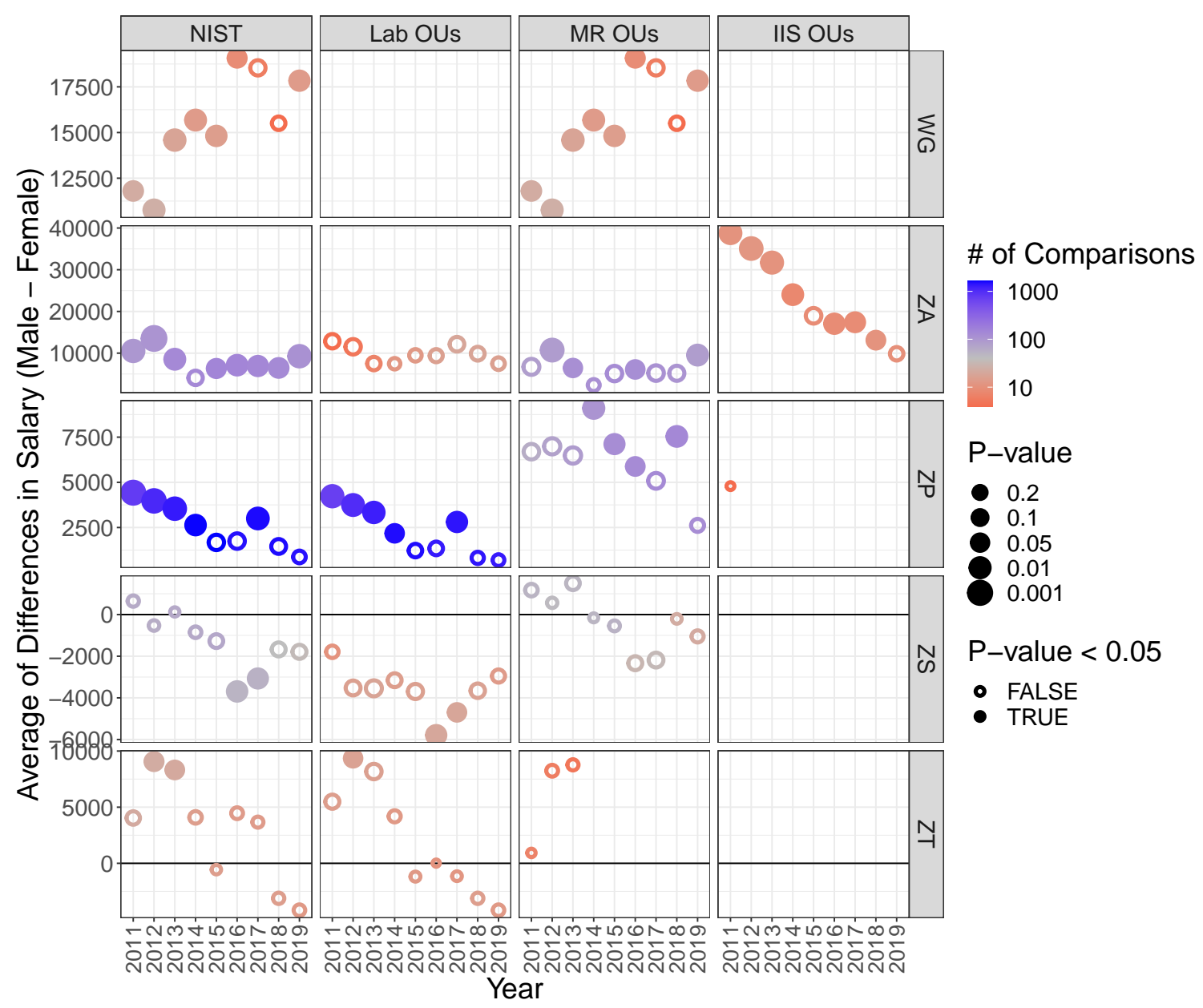

Fig. 7. High-level summary of annual salary differences between men and women at NIST.

\subsubsection{Salary differences for ZPs by education level and duty station}

In Fig. 9, we evaluate whether salary differences for the ZP employees vary by education level or duty station. Simultaneously breaking down the differences by OU, education level, and duty station leaves too little data in each combination, so we group OUs into Lab OU, MR, and IIS. We consider four levels of highest education - high school diploma, Bachelor's degree, Master's degree, and Doctorate and two duty stations - Colorado or Maryland.

Interesting patterns emerge with respect to both education level and duty station. The results show that:

- Salary differences among ZP employees in MD at the Bachelor's education level favored men in all nine years, having trended downward from roughly $\$ 13,000$ in 2011 to about $\$ 5,000$ in 2019 . The few available comparisons in CO, however, suggest nearly equitable pay for the same education level. 


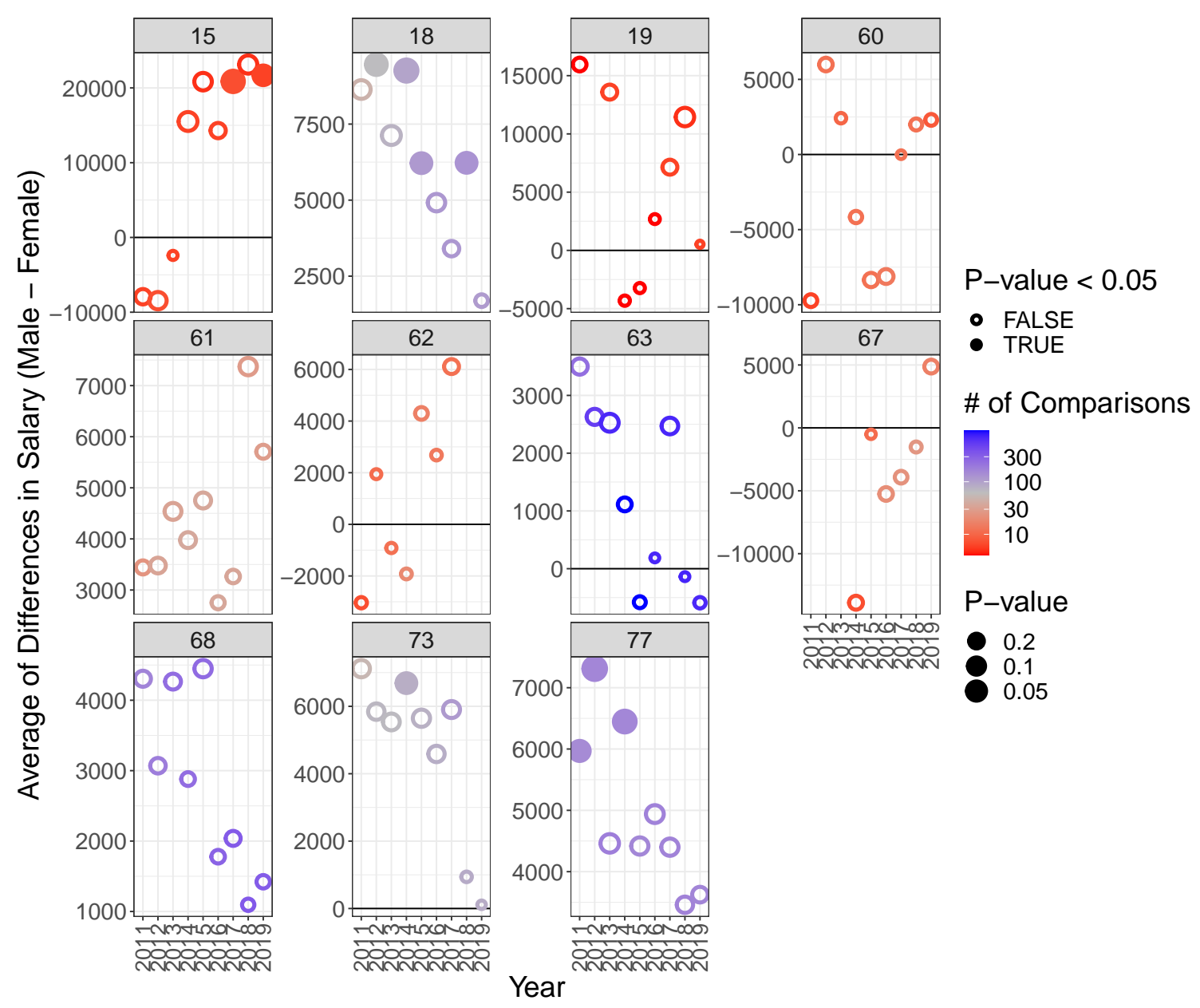

Fig. 8. Average differences in annual salary between men and women at NIST: Sweep across OUs for ZP employees.

- At the Doctorate level the roles reverse where both MD and CO initially showed salary differences favoring men by about $\$ 3,000$ in 2011. MD results then moved toward gender parity while $\mathrm{CO}$ results have mostly held steady at around $\$ 3,500$ favoring men.

- For the Master's level across NIST, differences seen among MD employee salaries favor men by roughly $\$ 2,500$ to $\$ 5,500$ each of the nine years, though each of these points had $\mathrm{p}$-values greater than 0.05 . The limited data from $\mathrm{CO}$ show salary differences favoring women by $\$ 15,000$ in 2019 .

\subsubsection{Salary differences for ZPs by education level within OUs}

We repeated the analysis of education level for each of the three largest OUs $(63,68$, and 77) and provide the results in Fig. 10. These results illustrate how salary differences can 


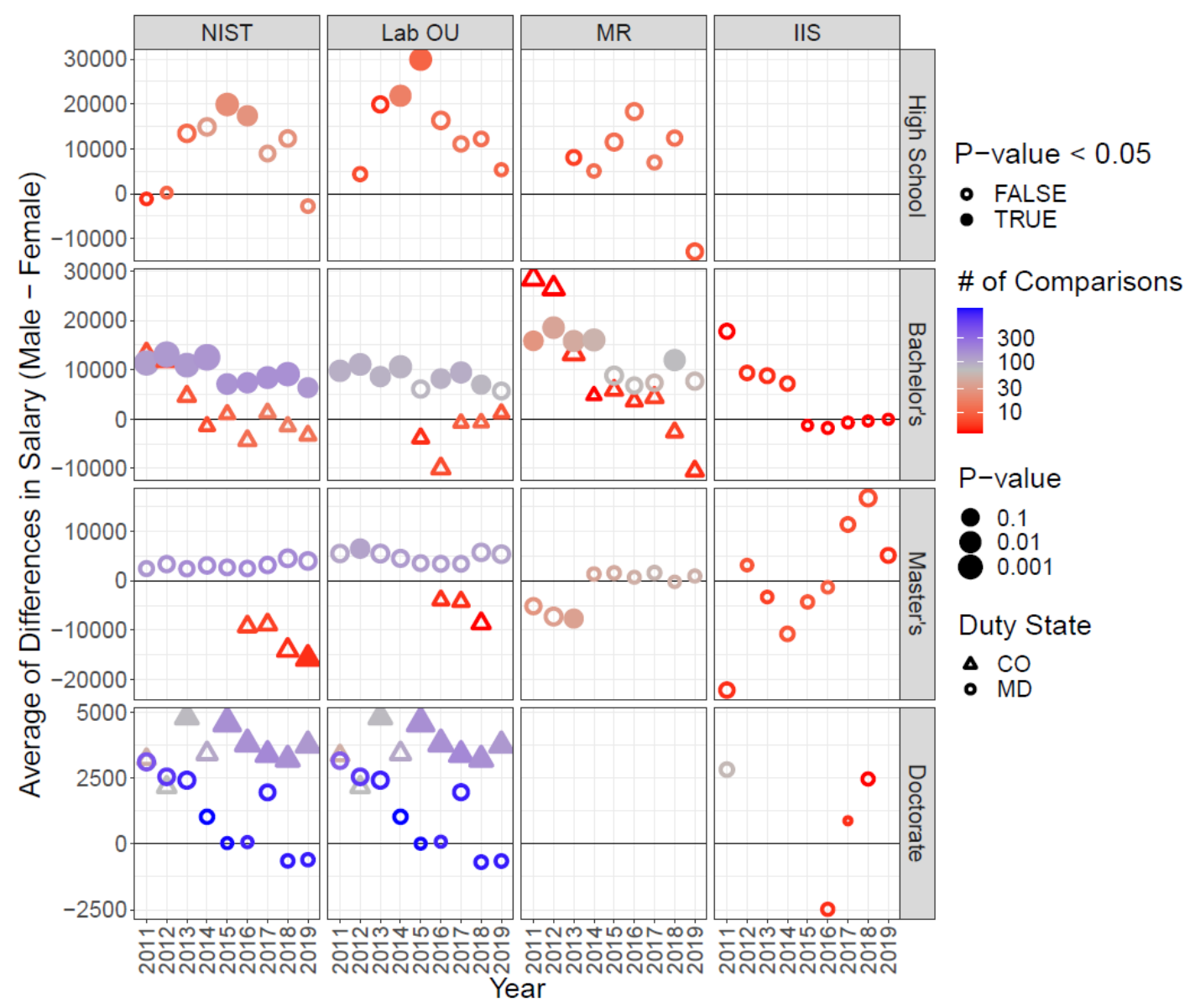

Fig. 9. Average differences in annual salary between ZP men and women at NIST, separated by OU type, duty state, and education level.

vary by education level within an OU. For example, average salary differences among ZP employees with Master's or Bachelor's degrees in OU 77 all favor men, while salary comparisons among OU 77 employees holding Doctorates appear to either exhibit gender parity or slightly favor women.

These results also show that differences can vary by individual OUs within an education level. For instance, at the Doctorate level, average differences in OU 68 all favor men (though the extent lessens from about $\$ 6,000$ in 2011 to about $\$ 1,000$ in 2019), but OUs 63 and 77 seem to generally exhibit gender parity.

\subsubsection{Salary differences for ZPs related to experience}

We assessed how salary differences are related to experience among ZP staff in laboratory OUs by evaluating smoothing splines that relate average salary to years in government for each gender, split by highest degree and year. For this analysis, we consider the salaries of individual employees with up to 30 years of experience. (Spline fits often became unstable 


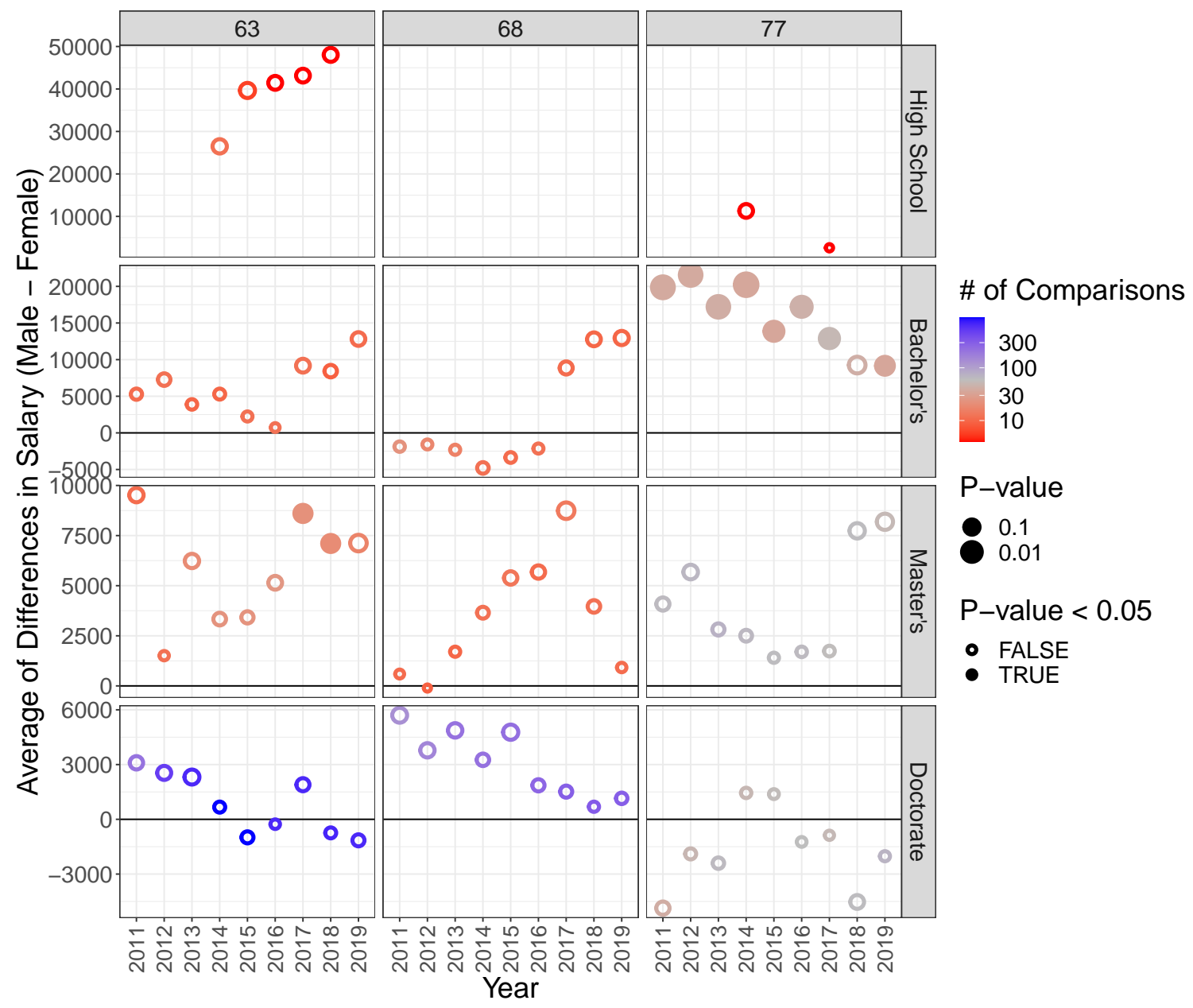

Fig. 10. Average differences in annual salary between ZP men and women separated by education level for OUs 63, 68, and 77.

beyond 30 years due to rapid drop off in the number of employees with that level of experience.) The results in Fig. 11 are consistent with the observations noted in discussion of Fig. 9 above. The results show that:

- Significant salary differences tend to favor men and appear most pronounced at the Bachelor's level of education and least pronounced at the Doctorate level. This figure reveals that salary differences appear most prominent among early and midgovernment careers (red smoothing curves mostly lie below blue smoothing curves during years of experience less than 20) and that these differences are largely stable across years 2011 through 2019. 


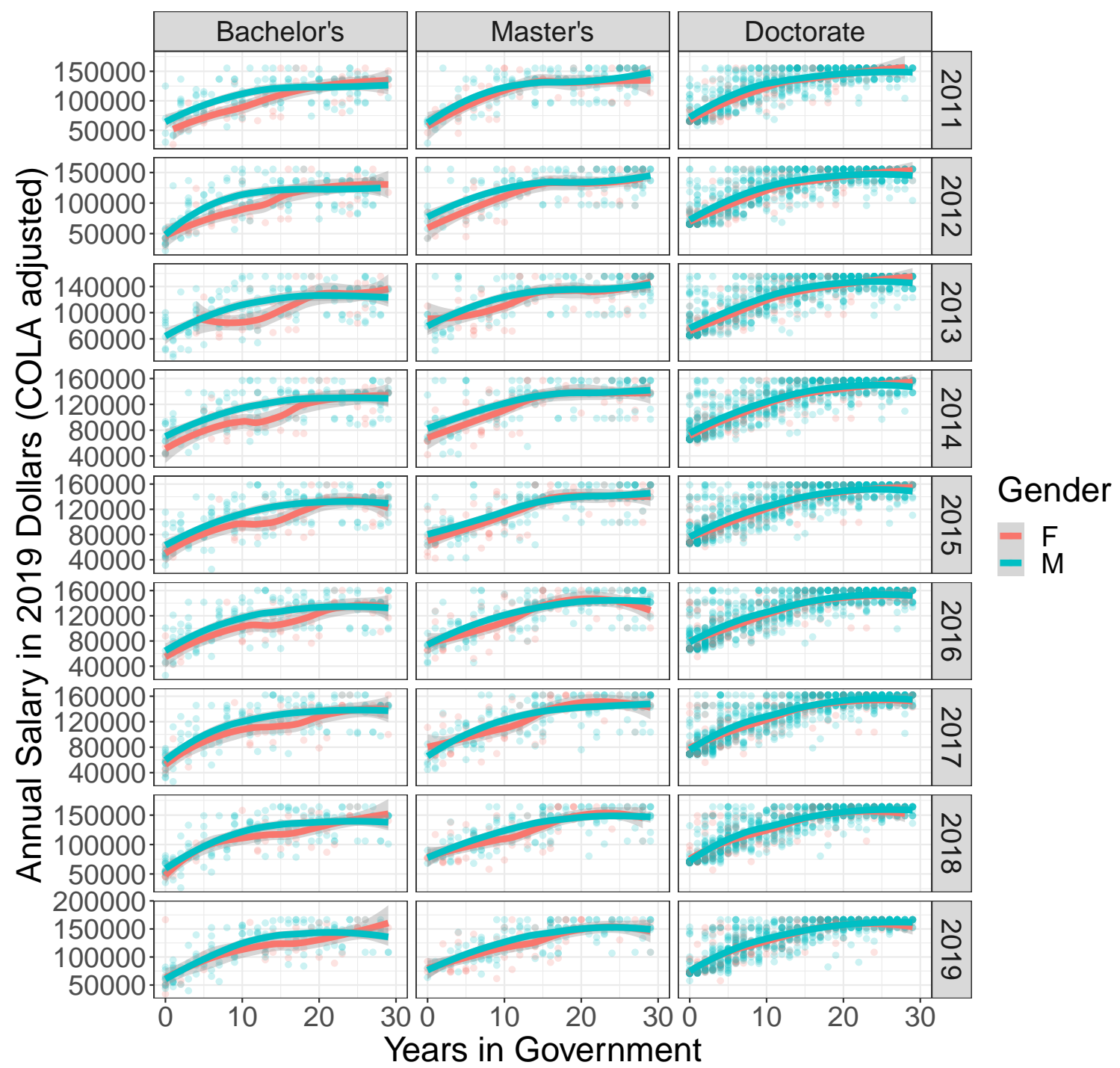

Fig. 11. Annual salary versus years in government for ZP men and women in laboratory OUs, split by highest degree.

\subsubsection{Salary differences for ZA employees}

In Fig. 12, we see that average salary differences for the ZA employees also vary by OU. The results show that:

- Of the 63 salary comparisons provided in Figure 12, 50 of the differences are positive, meaning salary differences favor men. This is, consistent with the high-level summary shown in Fig. 7.

- For OUs 10,48 , and 68 , the average salary differences favor men in all nine years, but display a negative trend over the nine years. 
- OUs 16 and 14 have the most pairings of comparable men and women and both show average salary differences favoring men in all but one year.

- OU 13 shows a steadily increasing trend that has favored men since 2016, though very few direct comparisons were available for this OU.

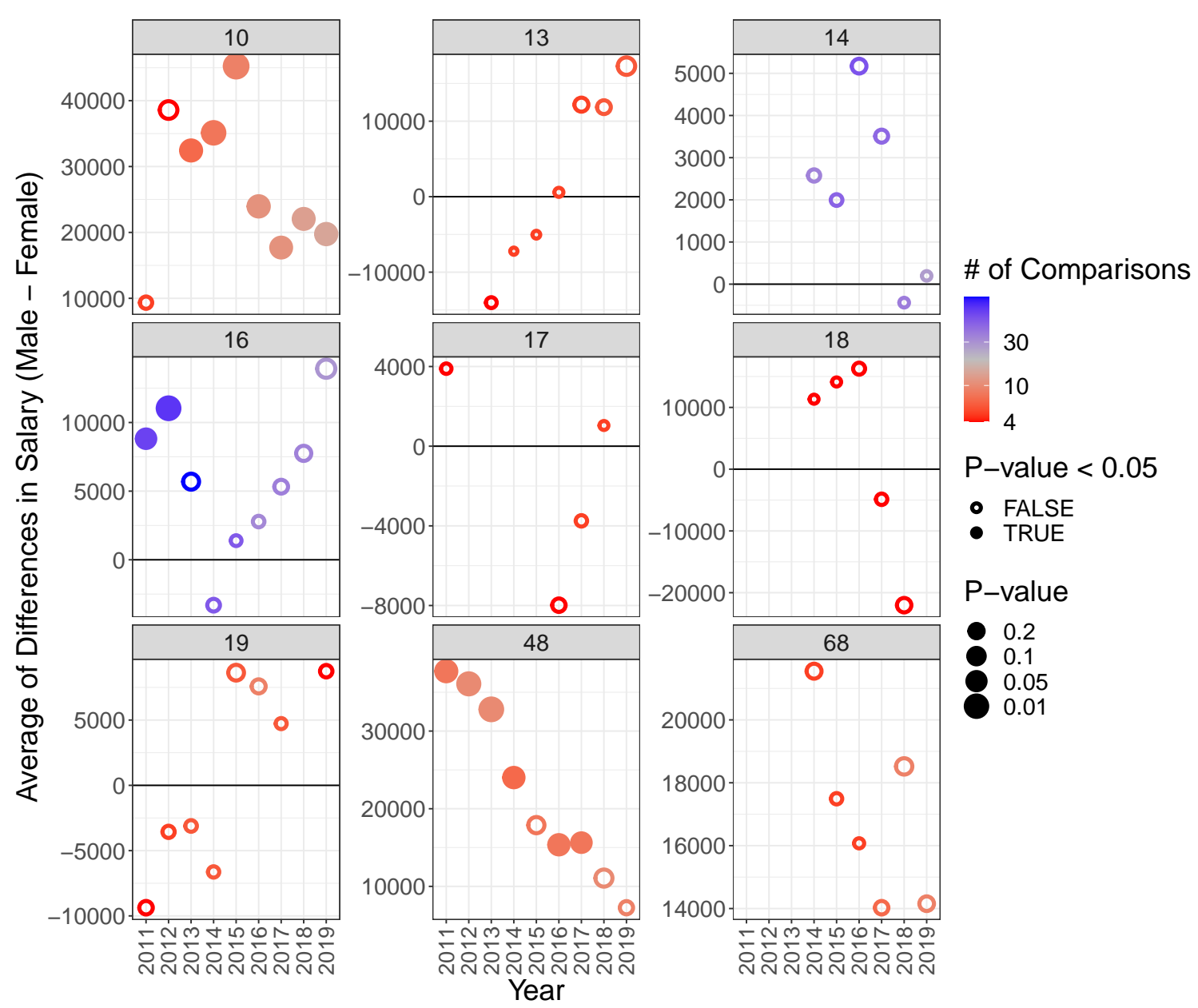

Fig. 12. Annual salary differences between men and women at NIST: Sweep across OUs for ZA employees.

\subsection{Gender differences in Pay Band}

To examine gender differences in pay band between comparable men and women, we conducted the same type of analyses based on direct comparisons and smoothing splines as were shown in the previous section when assessing salary differences. (When defining which employees were comparable in terms of pay band we required that amount of experience, degree, OU, and pay plan match, but duty station was not considered.) In general, 
the results for pay band differences qualitatively mirrored the results we saw for salary differences. This is not surprising given that the average difference in pay band for each comparable group is highly correlated with the average difference in salary for that same comparable group.

Figure 13 illustrates the correlation between average pay band differences and average salary differences for several combinations of pay plan and education level.

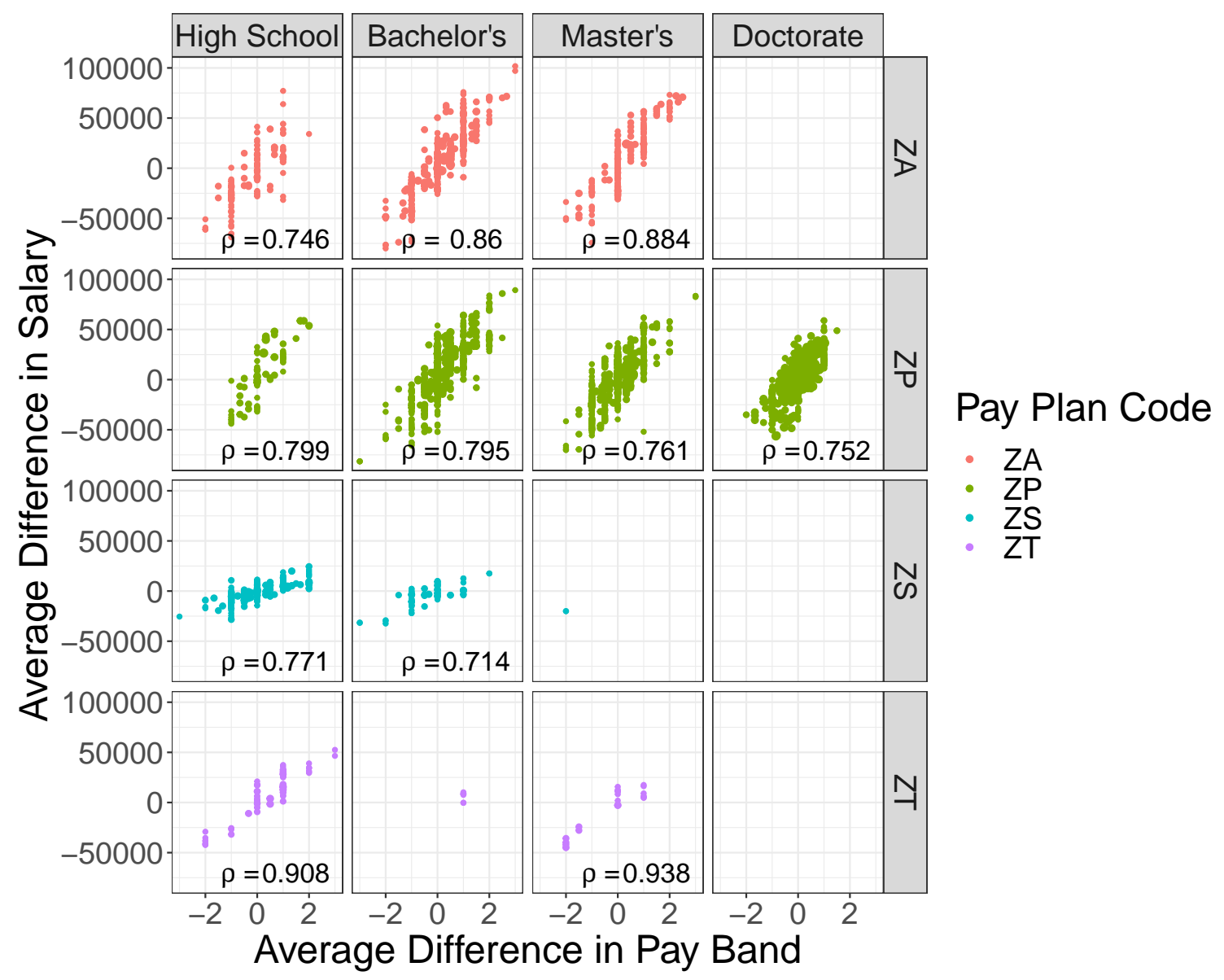

Fig. 13. Relationship between pay band differences and salary differences. Pearson's correlation coefficient is provided for each combination of pay plan and education level that had at least 10 distinct comparable groups.

\subsubsection{Pay Band versus years in government}

In addition to the direct comparison and spline smoothing approaches, we also evaluated the chance that $\mathrm{ZP}$ and ZA employees have reached pay bands IV and V versus their years in government. We applied survival analysis methods to construct curves for men and women, respectively, that relate the chance of having reached the considered pay band to the number 
of years worked in government. In Fig. 14, we present the results of the survival analysis for ZP employees with Bachelor's degrees, Master's degrees, or Doctorates, respectively. These results show that:

- ZP women reach pay band IV more slowly than ZP men at each level of education. The difference is largest at the Bachelor's level and smallest at the Doctorate level, which mirrors the ZP salary trends described in Sec. 3.3.

- A smaller fraction of ZP women ultimately reach pay band V than ZP men. Again, this difference is most pronounced at the Bachelor's level.

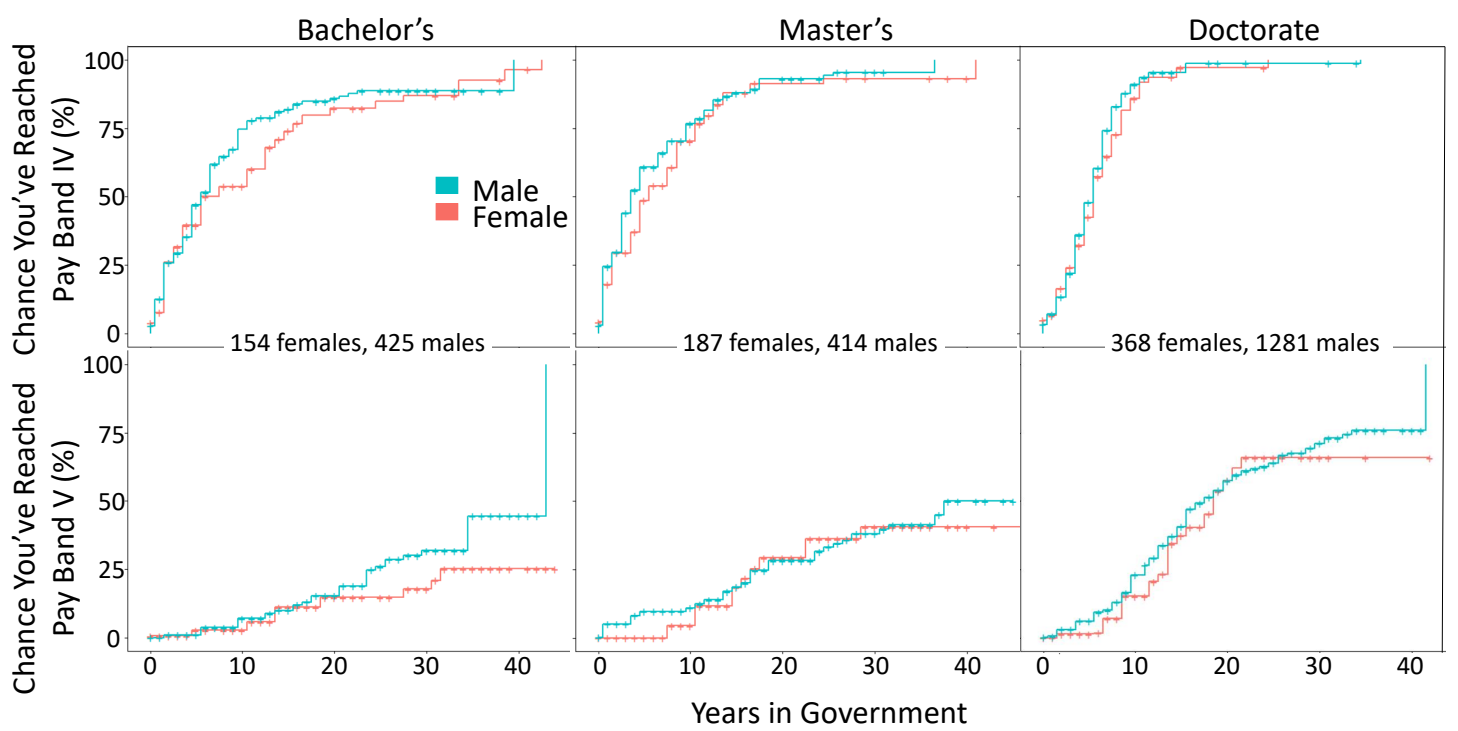

Fig. 14. Chances of achieving pay band IV (top) and V (bottom) versus years in government for ZP employees at NIST. Results are presented by gender (color) and education level (left Bachelor's degree; center - Master's degree; right - Doctorate). The number of male and female employees represented in the results is reported in each column.

In Fig. 15, we present results from applying the same survival analysis to data for ZA employees with high school diplomas, Bachelor's degrees, and Master's degrees, respectively. These results show:

- ZA women with Bachelor's or Master's degrees tend to reach pay band IV more slowly than ZA men with the same level of education,

- ZA women with high school diplomas tend to reach pay band IV more quickly than ZA men with high school diplomas.

- For all three education levels, women tend to spend less time at pay band V throughout the first 30 years of government employment than men do. 
- After 30 years, a higher percentage of women with Bachelor's or Master's degrees reached pay band $\mathrm{V}$ than men with the same level of education.

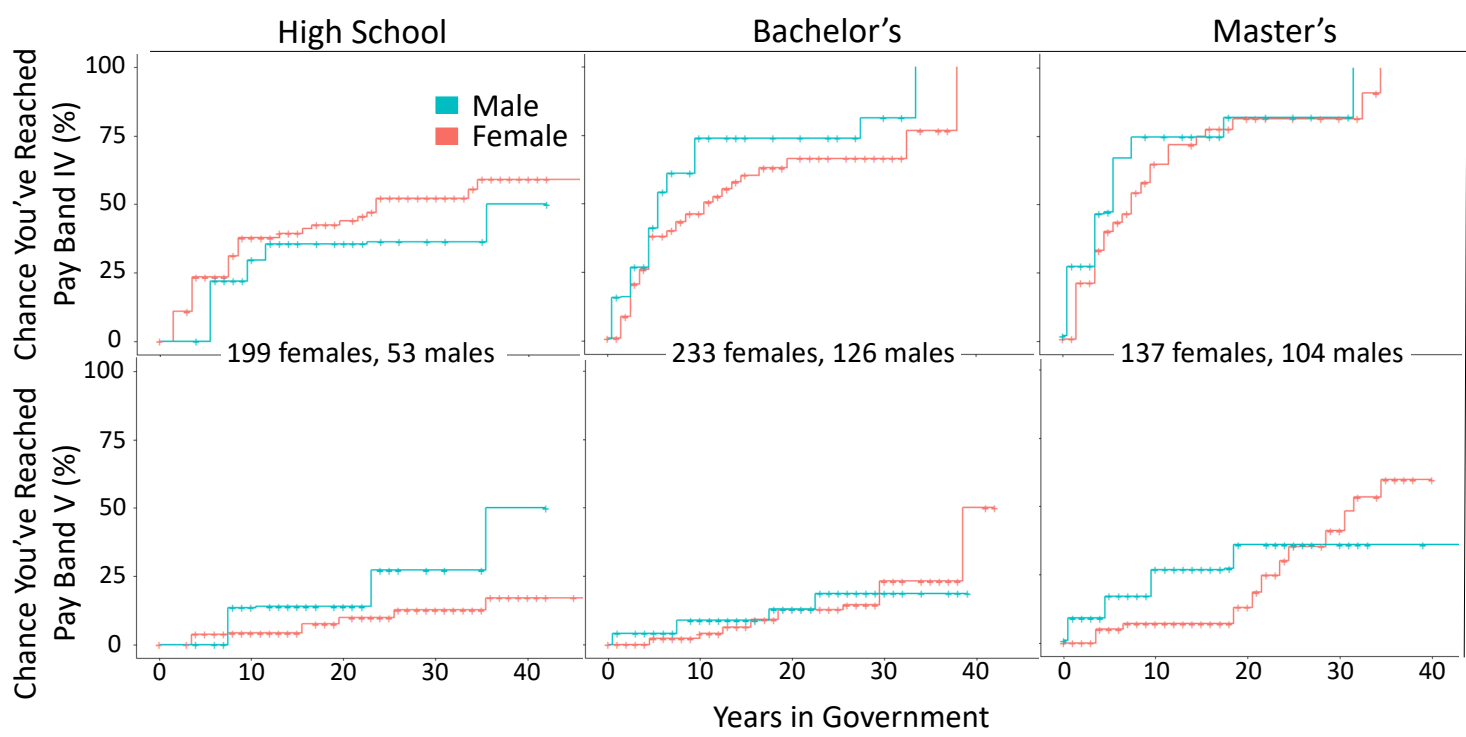

Fig. 15. Chances of achieving pay band IV (top) and V (bottom) versus years in government for ZA employees at NIST. Results are presented by gender (color) and education level (left - High school graduate; center - Bachelor's degree ; right - Master's Degree). The number of male and female employees represented in the results is reported in each column.

\subsection{Gender differences in Supervisor Level}

To assess potential gender imbalances in the rate at which males and females hold supervisory positions, we apply survival analysis to the HR data reporting each employee's years of government service and supervisory position status. As shown in Fig. 16, we use these tools to construct curves for men and women, respectively, that relate the chance of having been a supervisor at any point during 2011 to 2019 to the number of years worked in government. The results of these analyses show that for:

- ZP staff, males and females have roughly equal chances of being a supervisor at any given point in their careers.

- ZA and ZS employees, however, male employees become supervisors at roughly twice the rate of women throughout the first 20 years of service in government.

\section{Discussion}

The overall goal of this research effort aims to identify the contributing factors, attitudes, and processes that result in barriers for women at NIST. Using demographic data collected 


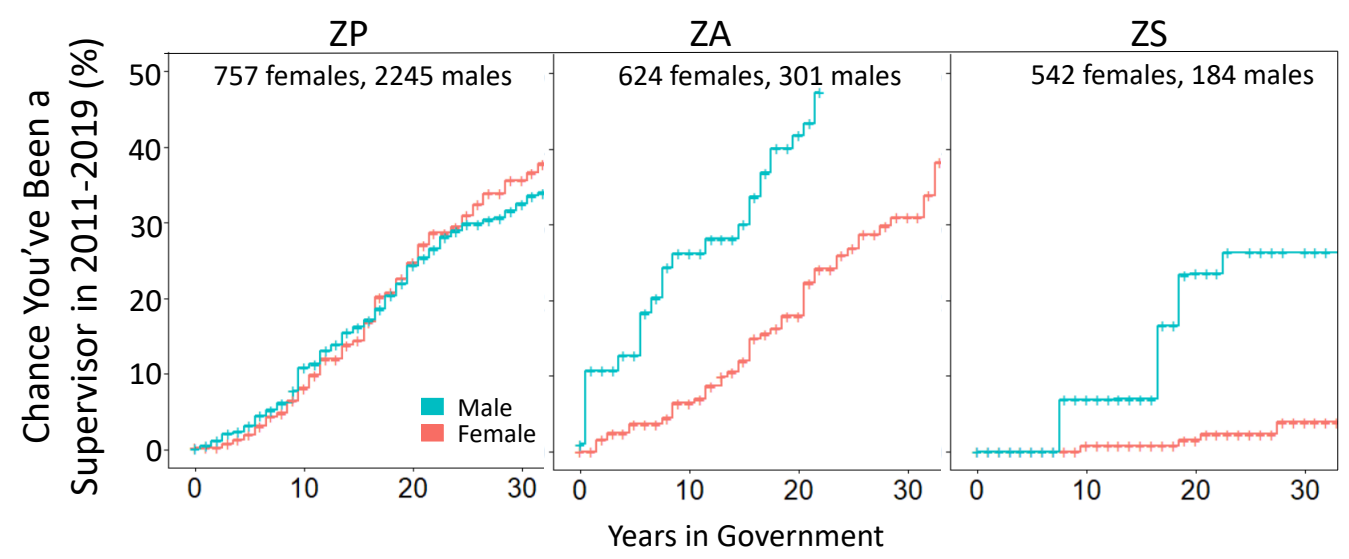

Fig. 16. Chance an employee has been a supervisor given their years in government for ZP, ZA, and ZS staff, respectively. The number of male and female employees represented in the results is reported in each panel.

by HR, we examined possible trends between genders that may provide the organization with insights about how inequalities manifest themselves in order to measure how the environment changes over time. There are decades worth of research in the field of gender inequality, exploring how cultural biases contribute to segregation and discrimination against women. These studies show that gender stereotypes and the perception of women in the workplace often limit women's advancement along with creating barriers for women to succeed in career related interests and choices.

We identified several imbalances that contribute to the inequality of women at NIST.

- NIST is consistently hiring more men than women for the ZP and ZT pay plans, a trend that has changed very little over the nine years analyzed. The gender distribution for the pool of new NIST ZP employees in STEM fields roughly matches those from the corresponding pools of doctorate recipients from 2017-2018.

- Salaries generally favor men in ZA, ZP, and WG pay plans.

- Salaries for ZP employees appear to be trending toward gender parity, while salary differences between male and female ZA employees appear to be holding steady and differences for WG employees may be increasing.

- Salaries for ZS employees exhibited near parity until 2014 and may now be favoring women.

- Among ZT employees, salary differences favored men before 2015 and more recently have either favored women or exhibited near parity. 
- ZP women reach pay band IV more slowly than men at each level of education. ZA women with Bachelor's or Master's degrees tend to reach pay band IV more slowly than ZA men with the same level of education

- A smaller fraction of ZP women ultimately reach pay band V than ZP men. This difference is most pronounced at the Bachelor's level.

- Compared to entry level positions, the percentage of women is much smaller in the highest levels of management and in SES, ST and SL appointments, indicating a glass ceiling/broken rung for women.

There were no discernible differences with respect to performance ratings for ZP employees and performance bonuses in general. Among ZS federal employees, a higher percentage of women receive the highest performance ratings than do men.

Although the doors to professional occupations were formally opened for women after World War II, gender inequalities still exist. The number of women in science related fields is often far lower than the number of men, resulting in a large gender gap. As the NIST HR data shows, there are more women in the ZA/ZS pay plans, $70 \%$ and $77 \%$ respectively, compared to women in the ZP/ZT paths, $25 \%$ and $16 \%$ respectively. One result of this gender gap involves women being excluded from organizational positions of autonomy and authority.

Additionally, even though there is a larger population of females in the secretarial and administrative roles, males have a greater chance of becoming a supervisor compared to females. Not all leadership positions are created equally, and not all jobs have the same career advancement. This is evident in the ZS and ZA paths. Today, women still obtain fewer of the high visibility, critical opportunities. This acts as a barrier to reaching the highest levels of leadership.

Previous studies on gender inequality have shown that pay differences are not a result of gender bias but the more subtle mechanisms of segregating women into particular occupations that are less rewarding than those occupied by men. Gender pay gaps persist around the world with women on average earning $81 \%$ of what their male counterparts earned. Our findings also identified a pay gap for women in the ZP and ZA pay plans at NIST. For both these pay plans women made less than their male counterparts. This apparent imbalance was most severe at the Bachelor's and Master's education levels, where the average salary differences favored men by $\$ 6,000$ and $\$ 4,000$, respectively.

\section{Conclusions}

The results of this study demonstrate that women at NIST experience both the broken rung and the glass ceiling. Because men outnumber women at the first supervisory level, in NIST's case the group leader position where $22 \%$ are women (women are $35 \%$ of NIST workforce), there are fewer women to promote to the next level and the numbers of women available for promotion continues to decrease as women move up the ladder. In fact, women 
experience a form of the broken rung early with respect to advancement into the higher bands limiting their opportunities for leadership positions. Without intervention this situation is likely to persist. Intervention can take the form of intentionally establishing pipelines for advancement of women.

Gender inequality in organizations is a complex phenomenon that affects the hiring, pay, and promotion of women. The findings reported here show that overall, women at NIST are falling behind men in each of these categories. Our results suggest that workplace cultures of male-dominated professions contribute to barriers for the advancement of women.

While most organizations are experiencing the glass ceiling, broken rung, and salary differentials, NIST is further behind compared to most of the peer organizations we examined. For example, women make up a third of the total population at NASA, however, in terms of women in leadership positions $28 \%$ are in senior executive leadership positions and $16 \%$ are senior scientific employees. As described earlier, at NIST in July $202016 \%$ of senior leadership (SES) positions are occupied by women and only $5 \%$ of ST employees and NIST Fellows are women. NIST is also slightly behind Oak Ridge National Laboratory (ORNL). At ORNL, women make up $17.6 \%$ of their senior leadership and just $15.3 \%$ of women are in the research/technical management field.

According to the OPM website, the federal workforce employs 897,892 women or $44 \%$ of federal employees. Over the past few years, women have been hired at an increasing rate. The federal government is in competition with the private, non-profit, and academic sectors for key science, technology, engineering, and mathematics (STEM) personnel. There has been an increase in women in STEM related jobs from 64,574 in 2008 to 70,047 in 2015. The representation of women in senior executive positions increased 5\% from 2008 to 2015. These increasing trends are not reflected in the percentage of SES NIST employees who are female.

There have been numerous research studies on how to effectively support diversity and inclusivity in the workplace. This research enhances awareness of the existence of gender inequality at NIST and gender-specific barriers in career advancement. Our hope is to treat diversity and inclusivity like the business imperative it is.

\section{Acknowledgments}

We would like to acknowledge and thank those who have made this study possible. First, we would like to acknowledge the Associate Director of Laboratory Programs, Dr. James Olthoff, for the funding support and opportunity to perform this research. Additionally, we would like to acknowledge Mary Willett, Teresa Sorcek, Teresa Whiteside, and Jasmine Ventura of the Office of Human Resources Management for pulling and consolidating the 9 years of data from multiple sources. We would like to thank the many people at NIST who provided constructive feedback on previous versions of this paper, including Dennis Leber, Michael Frey, Christopher Szakal, and Teresa Whiteside. 


\section{References}

[1] NIST Town Hall - July 12, 2018. Available at https://tube.nist.gov/media/1_9qqio5z4.

[2] Demographic Data. Available at https://inet.nist.gov/adlp/nist-demographic-data.

[3] Managers and Supervisors Meeting on Inclusivity - April 30 , 2019. Available at https://tube.nist.gov/media/Managers+and+Supervisors+Meeting+on+Inclusivity+ -+April+30+\%2C+2019/0_oya1b7zh.

[4] Szakal C, Johnson F Salary Analysis to Provide Managers with Tools to Make Equitable and Fair Decisions, Internal NIST Presentation.

[5] Szakal C, Johnson F MML Equity and Inclusivity Presentation Series - Data and Tools, Internal NIST Presentation.

[6] Espinal L, Evans H, Lawson J Summary of Findings from the Inaugural Equity Café held in December 2018 at NIST Gaithersburg, February 2019, Available at https://inet.nist.gov/system/files/documents/2019/02/28/g_equity_cafe _ dec_2018_022719_final_v2.pdf.

[7] Espinal L, Evans H, Lawson J Summary of Findings from the Equity Café held in March 2019 at NIST Boulder, September 2019, Available at https://inet.nist.gov/ system/files/documents/2019/09/10/b_equity_cafe_mar_2019_final.pdf.

[8] A Long Way to Go. Available at https://inet.nist.gov/system/files/documents/2020/11/ 03/a-long-way-to-go_high-res.pdf.

[9] Monroe KR, Chiu WF (2010) Gender equality in the academy: The pipeline problem. PS: Political Science \& Politics 43(2):303-308.

[10] Lean In. Women in the Workplace 2019. Available at https://leanin.org/ women-in-the-workplace-2019\#reports.

[11] National Academies of Sciences, Engineering and Medicine (2020) Promising Practices for Addressing the Underrepresentation of Women in Science, Engineering, and Medicine: Opening Doors (National Academies Press), 1st Ed.

[12] Parker M (2020) National Academies of Sciences, Engineering, and Medicine. Workshop on Addressing the Underrepresentation of Women of Color in Tech Workshop: Day 2, Panel Session 3, Google Diversity. Available at https:/www.nationalacademies.org/event/05-15-2020/ addressing-the-underrepresentation-of-women-of-color-in-tech-day-2.

[13] Lee BY (2020) National Academies of Sciences, Engineering, and Medicine. Workshop on Addressing the Underrepresentation of Women of Color in Tech Workshop: Day 2, Panel Session 3, Uber Diversity. Available at https://www.nationalacademies.org/event/05-15-2020/ addressing-the-underrepresentation-of-women-of-color-in-tech-day-2.

[14] Matthai M, Vasko D (2020) It's a Journey: Creating A culture of inclusion at Rockwell Automation, NIST seminar.

[15] National Institute of Standards and Technology Report by the Ad Hoc Affirmative Employment Committee for Female Scientists and Engineers August 1, 1993. Available at https://inet.nist.gov/files/pdf/womensreport. 
[16] Table 318.30. Bachelor's, master's, and doctor's degrees conferred by postsecondary institutions, by sex of student and discipline division: 2017-18. Available at https: //nces.ed.gov/programs/digest/d19/tables/dt19_318.30.asp?current=yes.

\section{Supporting Information}

\section{Starting Salary}

As shown in Fig.17, we examined the median starting salary among men and women for each combination of pay plan (ZA, ZP, ZS, or ZT) and pay band, which is used as a coarse representation of education level and past work experience. For each combination of pay plan and pay band, the median starting salaries of male and female employees tend to closely follow one another and often cross over one another between 2011 and 2019. One noticeable observation from examining new ZP hires in laboratory OUs was that 52 total men were hired at pay band $\mathrm{V}$ compared to 10 total women (including 25 men and no women from 2013 to 2015).

\section{Performance Bonus Ratings}

We examined performance rating distributions by pay plan for male and female employees at NIST. As summarized in Fig. 18, for ZP, ZA, and ZT pay plans, the percentage of males and females employees earning the highest rating tends closely follow one another and crosses over at some point between 2011 and 2019, suggesting approximate gender parity. For the ZS pay plan, a higher percentage of women receive each of the top two ratings than do men in each of the nine years. This suggests that women are generally rated more favorably than are men in the ZS pay plan.

We further examined performance rating distributions for ZP employees within each of the three largest OUs. As Fig. 19 shows, these performance ratings appear to mostly exhibit gender parity, with curves remaining close to one another and crossing throughout years from 2011 to 2019.

\section{Pay Band Differences}

As mentioned in the main text, the general findings from analyzing pay band differences between gender among comparable employees mirror those presented for salary differences. In Fig. 20, we provide a general overview of pay band differences analogous to Fig. 7 in the main text, which focused on salary differences. From Fig. 20, it is clear that there are more positive differences than negative for the WG, ZP, and ZA pay plans, suggesting for these sections of NIST men tend to advance pay bands faster than women within the same OU, with the same level of education and years of government experience.

As shown in Fig. 21, applying the smoothing spline analysis to pay band for ZP employees in laboratory OUs also produces very similar results to those seen when the same 


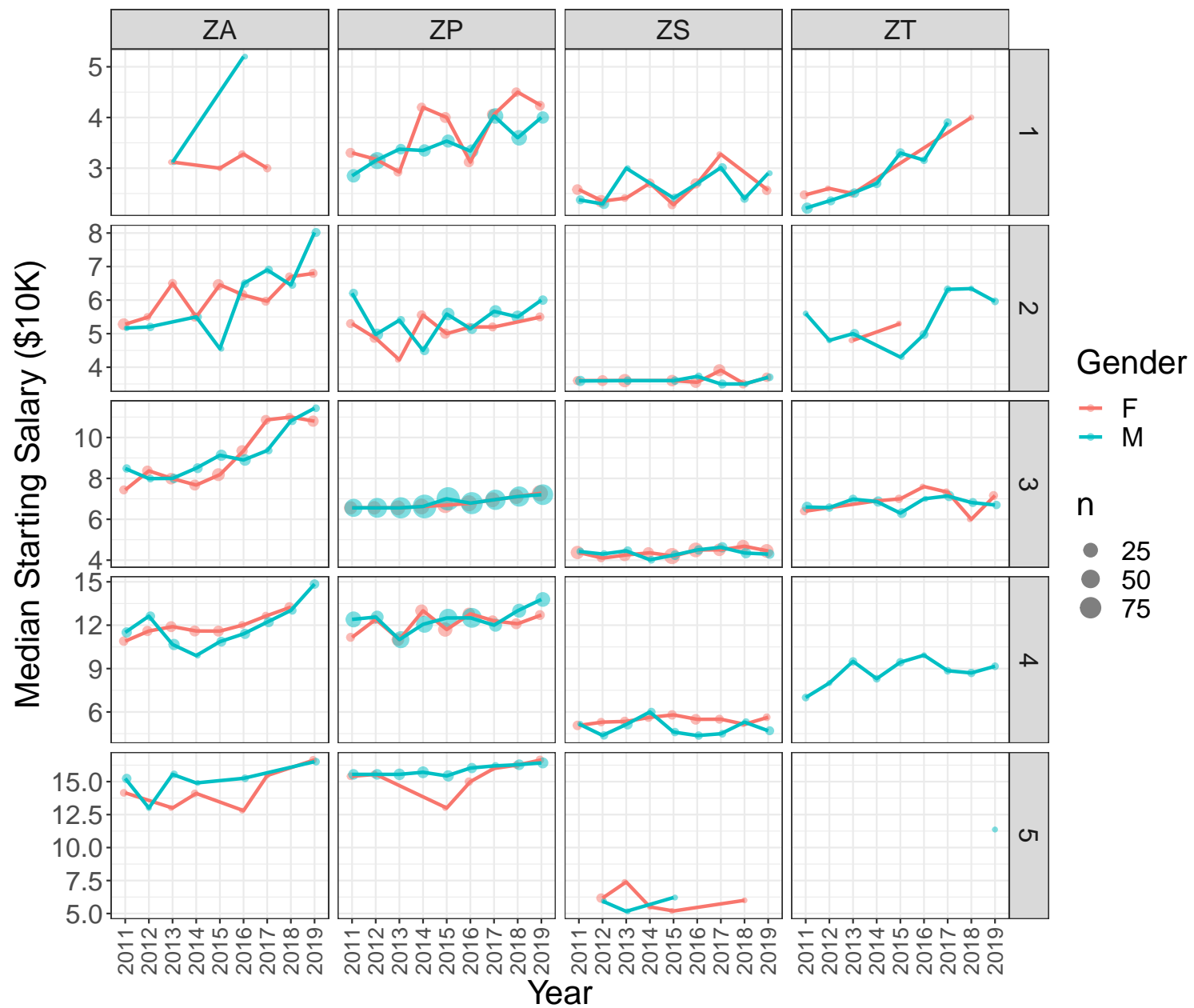

Fig. 17. Median starting salary for newly hired men and women split by pay band and pay plan.

analysis was applied to salary (main text Fig. 11). Pay band differences tend to favor men and appear most pronounced at the Bachelor's level of education and least pronounced at the Doctorate level. This figure again suggests that pay band differences appear most prominent among early and mid government careers (red smoothing curves mostly lie below blue smoothing curves during years of experience less than 20) and that these differences are largely stable across years 2011 through 2019. 


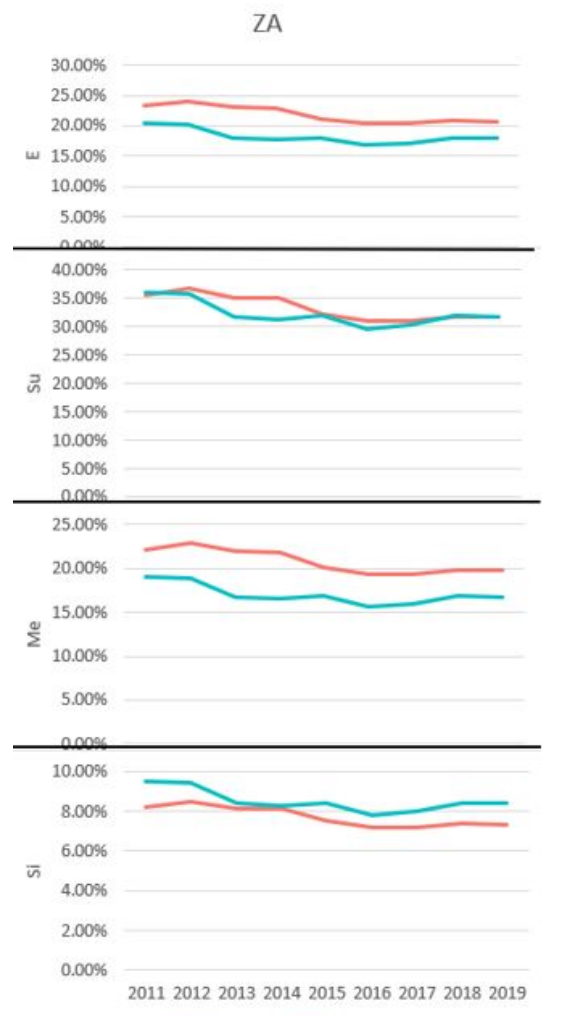

—Female —Males

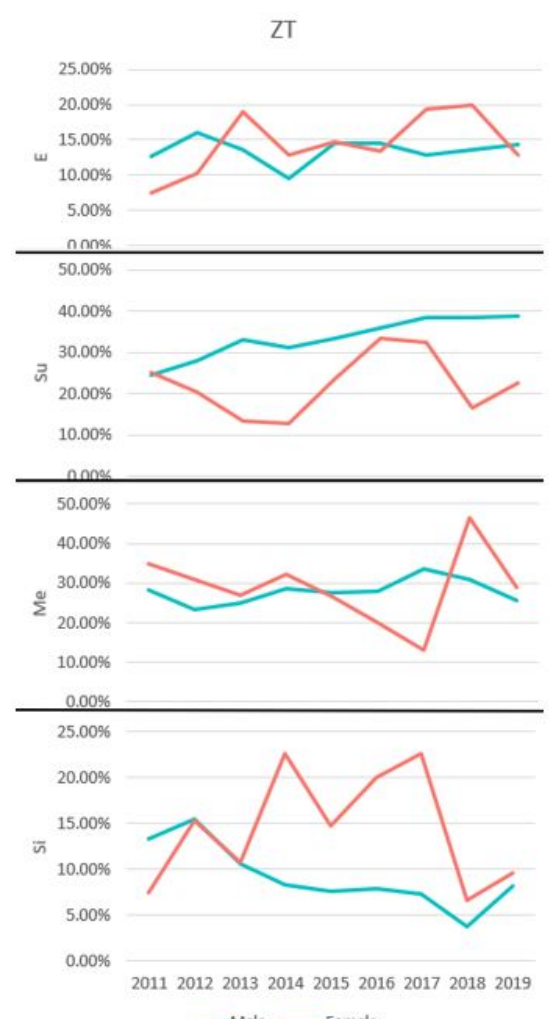

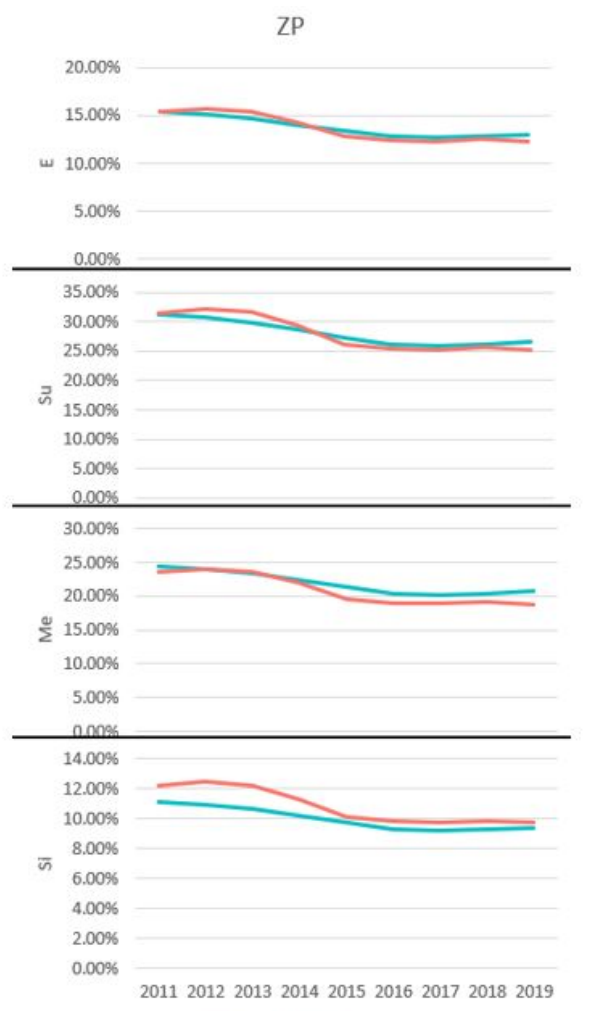

—Male _Female

ZS

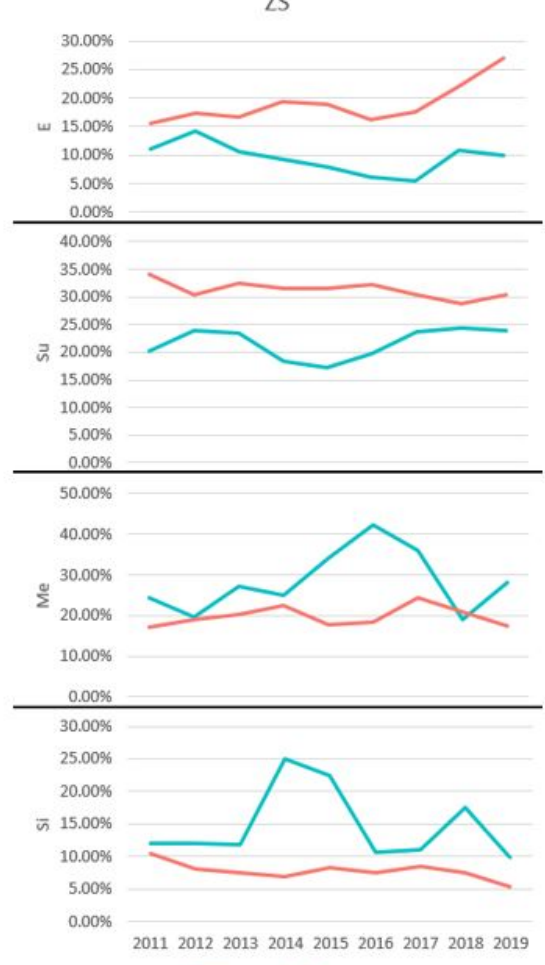

—Male —Female

Fig. 18. Annual Performance Rating between meg and women at NIST: Top performance ratings were selected for analysis. 

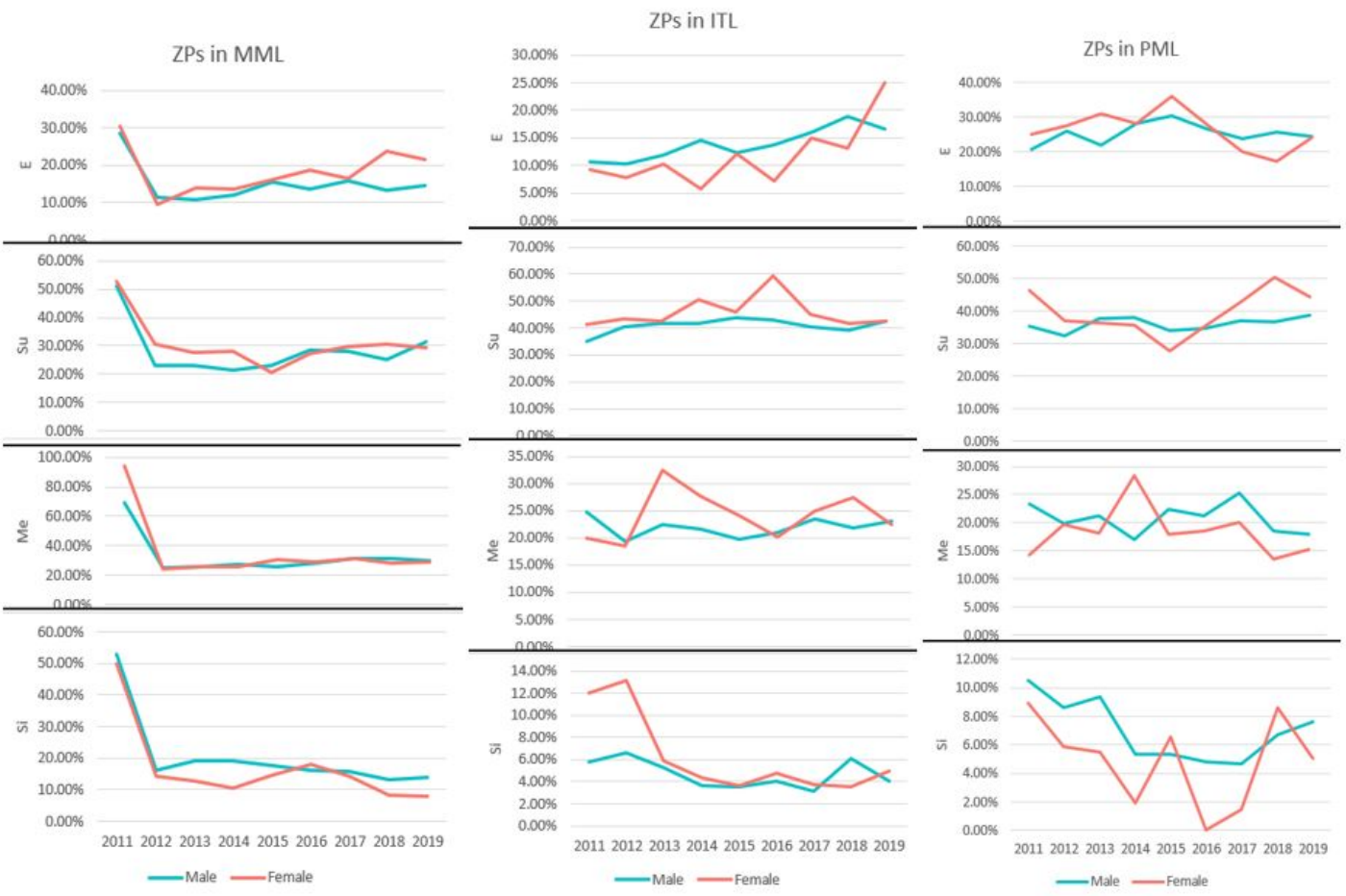

Fig. 19. Annual Performance Rating between ZP men and women in the largest three OUs: Top performance ratings were selected for analysis. 


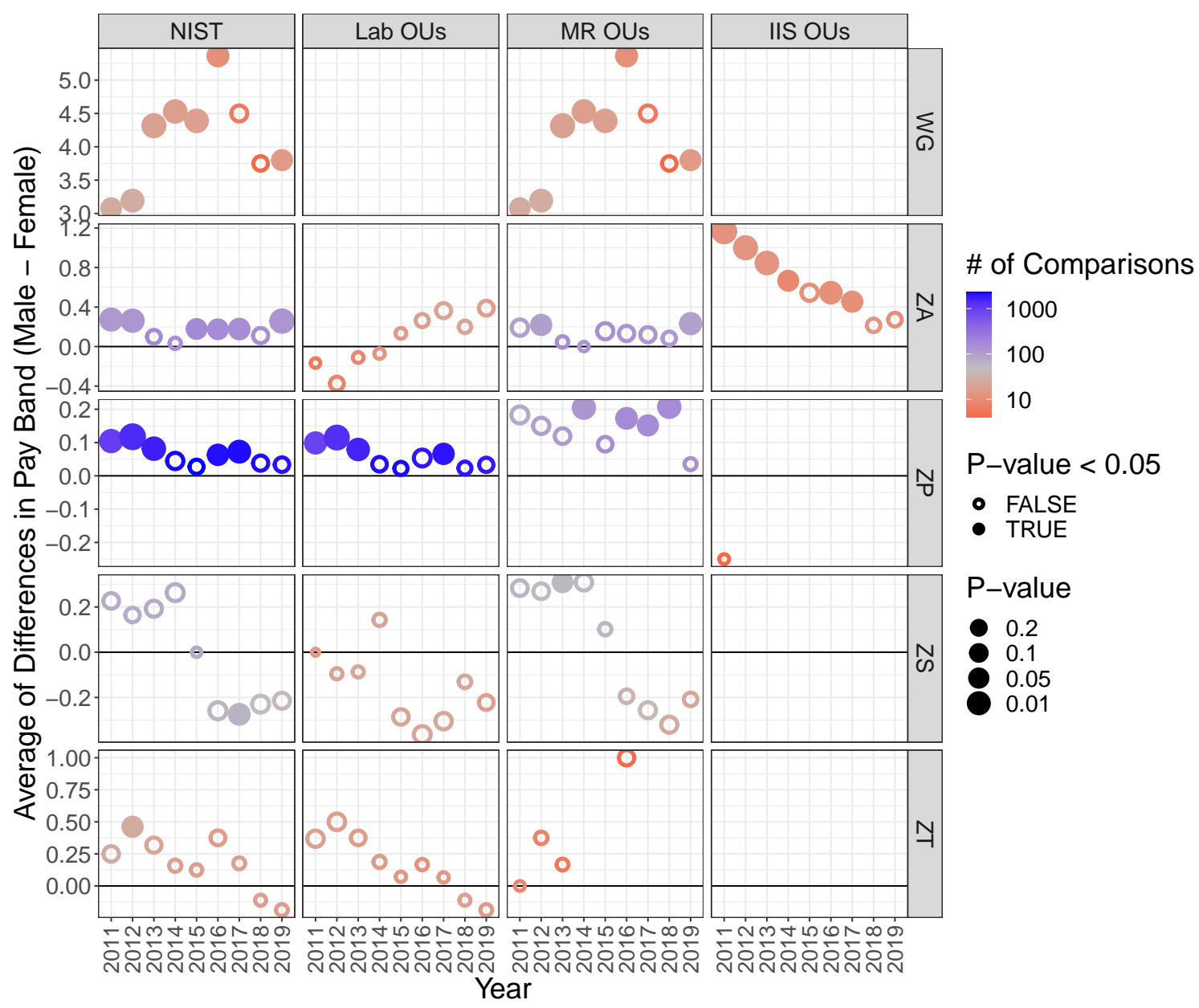

Fig. 20. High-level summary of pay band differences between men and women at NIST. 


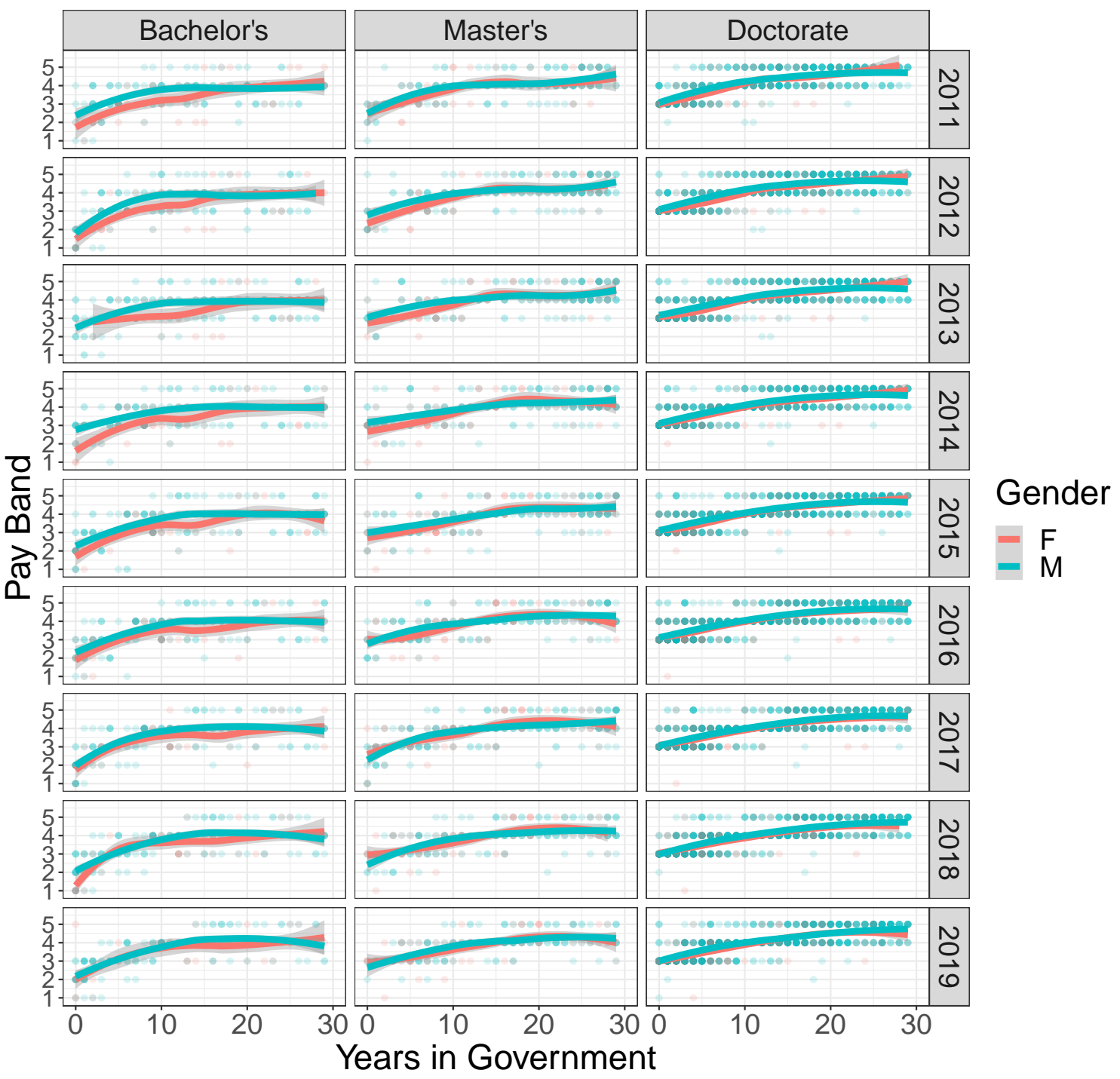

Fig. 21. Pay band versus years in government for ZP men and women in laboratory OUs, split by highest degree. 